\title{
Numerical modelling of free field traffic-induced vibrations
}

\author{
G. Lombaert ${ }^{\mathrm{a}, *}$, G. Degrande ${ }^{\mathrm{a}}$, D. Clouteau ${ }^{\mathrm{b}}$ \\ ${ }^{\mathrm{a}}$ Department of Civil Engineering, Katholieke Universiteit Leuven, W. de Croylaan 2, B-3001 Heverlee, Belgium \\ ${ }^{\mathrm{b}}$ Laboratoire de Mécanique des Sols, Structures et Matériaux, Ecole Centrale de Paris, F-92295 Châtenay-Malabry, France
}

Accepted 11 May 2000

\begin{abstract}
This paper deals with the numerical modelling of free field traffic-induced vibrations during the passage of a vehicle on an uneven road. The road unevenness subjects the vehicle to vertical oscillations that cause dynamic axle loads. The latter are calculated from the vehicle transfer functions and the frequency content of the road profile as experienced by the vehicle axles. A transfer function between the source and the receiver that accounts for the dynamic interaction between the road and the soil is used to calculate the free field response. Its calculation is based on a dynamic substructure method, using a boundary element method for the soil and an analytical beam model for the road. The methodology is validated with analytical results and is finally illustrated by a numerical example where the free field vibrations during the passage of a vehicle on a traffic plateau are considered. (C) 2000 Elsevier Science Ltd. All rights reserved.
\end{abstract}

Keywords: Numerical modelling; Traffic-induced vibrations; Vehicle transfer functions

\section{Introduction}

Traffic-induced vibrations are a common source of environmental nuisance as they may cause malfunctioning of sensitive equipment, discomfort to people and damage to buildings. They are mainly due to heavy lorries that pass at relatively high speed on a road with an uneven surface. Interaction between the wheels and the road surface causes a dynamic excitation, which generates waves that propagate in the soil and impinge on the foundations of nearby structures. Wave propagation is of great importance as it couples the source and the receiver. The focus in this paper will, therefore, be on the prediction of traffic-induced vibrations in the free field.

The dynamic axle loads are determined by the vehicle dynamics, the road unevenness and the road flexibility. As the road is much stiffer than the vehicle's suspension or tyres $[5,17,30]$, the calculation of the dynamic axle loads is in a first approximation uncoupled from the calculation of the soil response.

For linear vehicle models, vehicle frequency response functions (FRF) facilitate the calculation of the axle loads $[5,6,10,21]$ from the road unevenness and the equations of motion of the vehicle. Non-linear suspension characteristics

\footnotetext{
* Corresponding author. Fax: +32-16-32-1988.

E-mail address: geert.lombaert@bwk.kuleuven.ac.be (G. Lombaert).
}

or loss of contact cannot be modelled with these models, however [5].

The road unevenness is defined as the deviation of a travelled surface from a true planar surface that has characteristic dimensions that affect ride quality, vehicle dynamics, dynamic pavement loads and pavement drainage [36]. The road unevenness can be described in a deterministic way or in a stochastic way by a power spectral density (PSD) $[15,23]$. The PSD of the axle loads can be calculated from the vehicle FRF and the PSD of the road unevenness $[5,10,21]$.

The calculation of the response to moving loads is often based on the dynamic reciprocity theorem [33], where it is assumed that the road is invariant in its longitudinal direction. An extensive survey of calculation methods for solids or structures under moving loads is given by Frúba [16]. Grundmann et al. [18] have recently applied the dynamic reciprocity theorem for the calculation of free field vibrations due to a moving time-dependent load along the surface of a layered halfspace.

When the road unevenness is defined by a PSD, the response for a single vehicle passage is a non-stationary problem and a time-varying PSD should be calculated $[26,28]$. This stochastic solution procedure is based on time-frequency analysis. The calculation of the response for a continuous stream of vehicles, at a distance significantly greater than the mean vehicle spacing, can be considered as a stationary problem $[10,19,22,32]$. 
In most of the aforementioned references, the load is immediately applied to the soil and the dynamic soil-structure interaction between the road and the soil is disregarded. The latter can be accounted for by means of a substructuring technique $[2,3,9,34]$, where an analytical beam model is used for the road, while the soil is modelled by means of boundary elements $[7,8]$. The objective of this paper is to demonstrate how this substructure formulation can be coupled to a vehicle model to compute traffic-induced vibrations in the free field [27,28]. First, it is shown how the dynamic axle loads are computed using simple $2 \mathrm{D}$ vehicle models. Second, the transfer functions that describe the dynamic interaction between the road and the soil are derived. Third, these ingredients are used in the dynamic reciprocity theorem to compute the free field response due to a vehicle moving on a road, whose uneveness is described in a deterministic way. Next, the substructure formulation and the theory on moving loads are validated by means of the solution of Mandel and Avramesco [31] for the response at the surface of an elastic halfspace for a stationary moving load. The complete solution procedure is finally illustrated by a numerical example where the free field response due to the passage of a truck on a traffic plateau is considered.

The problem of moving loads has also received considerable attention in the field of railway-induced vibrations. Advanced track models have been proposed that are coupled with the soil through the sleepers and the ballast. Van den Broeck and De Roeck [35] and Knothe and Wu [25] have recently proposed very similar track models where a finite element model is used for the track and a boundary element formulation is used to calculate the impedance of the layered soil. Apart from through-soil coupling of the sleepers, different excitation mechanisms as quasi-static loading due to moving axles, parametric excitation, transient excitation due to rail joints and wheelflats and excitation due to wheel and rail roughness are incorporated.

\section{The dynamic axle loads}

Each longitudinal road profile is characterized by unevenness, which subjects the vehicle to vertical oscillations that cause dynamic axle loads. These dynamic axle loads are determined by the road profile, the vehicle characteristics and the vehicle speed.

\subsection{The vehicle dynamics}

Vehicle models consisting of discrete masses, springs and dampers have often been used and have proven good performance $[5,6,10,17]$. Either $2 \mathrm{D}$ or $3 \mathrm{D}$ vehicle models can be used. 2D vehicle models only account for the 2D plane motion of the vehicle, while 3D vehicle models include effects as vehicle rolling. As the contribution of vehicle rolling to the dynamic axle loads is expected to be small, a 2D model is sufficient [5].

A 2D 4 DOF vehicle model for a passenger car is shown

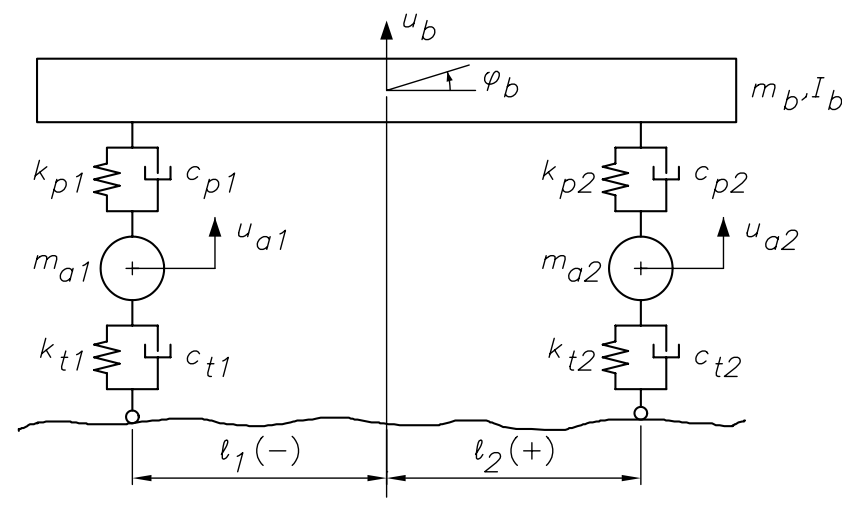

Fig. 1. 2D 4 DOF model for a passenger car.

in Fig. 1. A distinction is made between the vehicle body and the wheel axles, that are both assumed to be rigid inertial elements. The primary suspension system links the body and the axles, while the tyres connect the wheel axles to the road. Both the suspension system and the tyres are represented by a spring-dashpot system. More complex vehicle models are used to study vehicle ride behaviour, comfort or safety. The size of these models can successfully be reduced using the Irons-Guyan reduction technique, distinguishing between master and slave DOF [20].

The equations of motion of the vehicle can be written in the following generalized form:

$$
\begin{aligned}
{\left[\begin{array}{ll}
\mathbf{M}_{\mathrm{bb}} & 0 \\
0 & \mathbf{M}_{\mathrm{aa}}
\end{array}\right]\left\{\begin{array}{l}
\ddot{\mathbf{u}}_{\mathrm{b}} \\
\left.\ddot{\mathbf{u}}_{\mathrm{a}}\right\}
\end{array}\right.} & +\left[\begin{array}{ll}
\mathbf{C}_{\mathrm{bb}}^{\mathrm{p}} & \mathbf{C}_{\mathrm{ba}}^{\mathrm{p}} \\
\mathbf{C}_{\mathrm{ba}}^{\mathrm{p} T} & \mathbf{C}_{\mathrm{aa}}^{\mathrm{p}}+\mathbf{C}_{\mathrm{aa}}^{\mathrm{t}}
\end{array}\right]\left\{\begin{array}{l}
\dot{\mathbf{u}}_{\mathrm{b}} \\
\dot{\mathbf{u}}_{\mathrm{a}}
\end{array}\right\} \\
& +\left[\begin{array}{ll}
\mathbf{K}_{\mathrm{bb}}^{\mathrm{p}} & \mathbf{K}_{\mathrm{ba}}^{\mathrm{p}} \\
\mathbf{K}_{\mathrm{ba}}^{\mathrm{pT}} & \mathbf{K}_{\mathrm{aa}}^{\mathrm{p}}+\mathbf{K}_{\mathrm{aa}}^{\mathrm{t}}
\end{array}\right]\left\{\begin{array}{l}
\mathbf{u}_{\mathrm{b}} \\
\mathbf{u}_{\mathrm{a}}
\end{array}\right\} \\
= & \left\{\begin{array}{l}
\mathbf{F}_{\mathrm{b}}^{\mathrm{ext}} \\
\mathbf{F}_{\mathrm{a}}^{\mathrm{ext}}
\end{array}\right\}+\left[\begin{array}{ll}
\mathbf{0} & \mathbf{0} \\
\mathbf{0} & \mathbf{K}_{\mathrm{aa}}^{\mathrm{t}}
\end{array}\right]\left\{\begin{array}{l}
\mathbf{0} \\
\mathbf{u}_{\mathrm{r}}+\mathbf{u}_{\mathrm{w} / \mathrm{r}}
\end{array}\right\}+\left[\begin{array}{ll}
0 & 0 \\
0 & \mathbf{C}_{\mathrm{aa}}^{\mathrm{t}}
\end{array}\right] \\
& \times\left\{\begin{array}{l}
0 \\
\dot{\mathbf{u}}_{\mathrm{r}}+\dot{\mathbf{u}}_{\mathrm{w} / \mathrm{r}}
\end{array}\right\}
\end{aligned}
$$

where the vectors $\mathbf{u}_{\mathrm{b}}$ and $\mathbf{u}_{\mathrm{a}}$ collect the displacement components of the car body and the axles, respectively, while the vectors $\mathbf{F}_{\mathrm{b}}^{\text {ext }}$ and $\mathbf{F}_{\mathrm{a}}^{\text {ext }}$ contain external forces applied directly to the car body and the wheel axles. The superscripts $p$ and $t$ in the stiffness and damping matrices refer to the primary suspension and the tyres. $\mathbf{u}_{\mathrm{w} / \mathrm{r}}$ and $\mathbf{u}_{\mathrm{r}}$ collect the time histories of the road unevenness and the road displacements at the vehicle axles, respectively. The interaction forces $\mathbf{F}_{\mathrm{w} / \mathrm{r}}^{\mathrm{int}}$ between the vehicle axles and the road depend on the difference between the axle displacements $\mathbf{u}_{\mathrm{a}}$ and the sum of the irregularities $\mathbf{u}_{\mathrm{w} / \mathrm{r}}$ of the road surface and the road displacements $\mathbf{u}_{\mathrm{r}}$ at the axle positions:

$\mathbf{F}_{\mathrm{w} / \mathrm{r}}^{\mathrm{int}}=\mathbf{K}_{\mathrm{aa}}^{\mathrm{t}}\left[\mathbf{u}_{\mathrm{a}}-\left(\mathbf{u}_{\mathrm{r}}+\mathbf{u}_{\mathrm{w} / \mathrm{r}}\right)\right]+\mathbf{C}_{\mathrm{aa}}^{\mathrm{t}}\left[\dot{\mathbf{u}}_{\mathrm{a}}-\left(\dot{\mathbf{u}}_{\mathrm{r}}+\dot{\mathbf{u}}_{\mathrm{w} / \mathrm{r}}\right)\right]$ 
where $\mathbf{K}_{\mathrm{aa}}^{\mathrm{t}}$ and $\mathbf{C}_{\mathrm{aa}}^{\mathrm{t}}$ are diagonal matrices containing the stiffness and damping coefficients $k_{\mathrm{t} k}$ and $c_{\mathrm{t} k}$ of all axles $k$.

It has been shown before that the influence of the road displacements $\mathbf{u}_{\mathrm{r}}$ on the dynamic axle loads can be neglected, due to the high stiffness of the road with respect to the vehicle suspension and the tyres $[5,26]$. The calculation of the axle loads will therefore be based on the road unevenness and the vehicle dynamics only and will be decoupled from the road-soil interaction problem.

\subsection{The longitudinal road profile}

The road unevenness $u_{\mathrm{w} / \mathrm{r}}(y)$ represents the deviation of the pavement surface from a true planar surface at a point $y$ along the road. Local road irregularities as well as global road roughness can be described by a deterministic function $u_{\mathrm{w} / \mathrm{r}}(y)$.

A forward Fourier transformation of $y$ to the wavenumber $k_{y}$ results in the wavenumber domain representation $\tilde{u}_{\mathrm{w} / \mathrm{r}}(y)$ of $u_{\mathrm{w} / \mathrm{r}}(y)$ :

$\tilde{u}_{\mathrm{w} / \mathrm{r}}\left(k_{y}\right)=\int_{-\infty}^{+\infty} u_{\mathrm{w} / \mathrm{r}}(y) \exp \left(+\mathrm{i} k_{y} y\right) \mathrm{d} y$

Table 1 shows a classification of road roughness which is based on the wavelength $\lambda_{y}=2 \pi / k_{y}$ of the road irregularities [14]. The range of road unevenness, which is important for vehicle dynamics is characterized by wavelengths $\lambda_{y}$ between 0.5 and $50 \mathrm{~m}$. Since the size $p$ of the footprint of the tyre typically varies between 100 and $200 \mathrm{~mm}$ for passenger cars and trucks, the ratio $p / \lambda_{y}$ is small and the contact between the tyre and the road can be approximated as a point contact.

Global road roughness can also be described in a statistical way by a power spectral density (PSD) as in the ISO 8608 standard [23]. These PSD-curves can be used to generate an artificial road profile $u_{\mathrm{w} / \mathrm{r}}(y)$. A large number of deterministic simulations with different artificial profiles is needed, however, to calculate the statistical properties of the response for a single vehicle passage. An alternative and more efficient way to treat the stochastic description of the road unevenness consists in calculating the time-varying PSD of the response from the PSD of the axle loads, based on time-frequency analysis [26,28].

\subsection{The vehicle frequency response functions}

The distribution of $n$ axle loads can be written as the summation of the product of Dirac functions that determine the position of the force and a time-dependent function $g_{k}(t)$ :

$F_{w / r}^{i n t}(x, y, z, t)=\sum_{k=1}^{n} \delta(x) \delta\left(y-y_{k}-v t\right) \delta(z) g_{k}(t)$

$y_{k}$ is the initial position of the $k$ th axle load that moves with the vehicle speed $v$ along the $y$-axis. Since the road displacements $\mathbf{u}_{\mathrm{r}}$ can be neglected in the calculation of the inter-
Table 1

Classification of road roughness

\begin{tabular}{ll}
\hline Class & Range \\
\hline Microtexture & $\lambda_{y}<5 \times 10^{-4} \mathrm{~m}$ \\
Macrotexture & $5 \times 10^{-4} \mathrm{~m}<\lambda_{y}<5 \times 10^{-2} \mathrm{~m}$ \\
Megatexture & $5 \times 10^{-2} \mathrm{~m}<\lambda_{y}<0.5 \mathrm{~m}$ \\
Unevenness & $0.5 \mathrm{~m}<\lambda_{y}<50 \mathrm{~m}$ \\
\hline
\end{tabular}

action forces, the time history $g_{k}(t)$ of a single axle load is calculated from the contribution of all $n$ vehicle axles and the road surface profile:

$g_{k}(t)=\sum_{l=1}^{n} \int_{-\infty}^{t} h_{f_{k} u_{l}}(t-\tau) u_{w / r}^{l}(\tau) \mathrm{d} \tau$

The contribution of axle $l$ is calculated as the convolution integral of an impulse response function $h_{f_{k} u_{l}}(t)$, representing the time-history of the axle load at axle $k$ when a unit impulse excitation is applied to axle $l$, and the time history $u_{\mathrm{w} / \mathrm{r}}^{l}(t)$ of the road unevenness experienced by axle $l$. The latter follows from the longitudinal road profile $u_{\mathrm{w} / \mathrm{r}}(y)$, the initial axle position $y_{l}$ and the vehicle speed $v$ :

$u_{\mathrm{w} / \mathrm{r}}^{l}(t)=u_{\mathrm{w} / \mathrm{r}}\left(y_{l}+v t\right)$

The representation of the interaction force $\hat{g}_{k}(\omega)$ in the frequency domain results from the Fourier transform of Eq. (5):

$\hat{g}_{k}(\omega)=\int_{-\infty}^{+\infty} g_{k}(t) \exp (-\mathrm{i} \omega t) \mathrm{d} t=\sum_{l=1}^{n} \hat{h}_{f_{k} u_{l}}(\omega) \hat{u}_{\mathrm{w} / \mathrm{r}}^{l}(\omega)$

where $\hat{h}_{f_{k} u_{l}}(\omega)$ is the frequency response function (FRF) of the axle $k$ due to an excitation at axle $l[5,21]$. The FRFs are found by solving the equations of motion (1) of the vehicle in the frequency domain, where the external forces are set to zero and $\hat{\mathbf{u}}_{\mathrm{w} / \mathrm{r}}(\omega)$ represents a vector with a unit harmonic displacement applied to axle $l$. As the road deflection is neglected, the FRFs are calculated from the axle displacements as:

$\hat{h}_{f_{k} u_{l}}(\omega)=\left(k_{t k}+\mathrm{i} \omega c_{t k}\right)\left(\hat{u}_{a k}(\omega)-\delta_{k l}\right)$

with $\delta_{k l}$ the Kronecker delta. In Eq. (7), $\hat{u}_{\mathrm{w} / \mathrm{r}}^{l}(\omega)$ is the representation in the frequency domain of the unevenness experienced by axle $l$. It follows from the wavenumber domain representation $\tilde{u}_{\mathrm{w} / \mathrm{r}}\left(k_{y}\right)$ of the road profile $u_{\mathrm{w} / \mathrm{r}}(y)$ :

$\hat{u}_{\mathrm{w} / \mathrm{r}}^{l}(\omega)=\frac{1}{v} \tilde{u}_{\mathrm{w} / \mathrm{r}}\left(-\frac{\omega}{v}\right) \exp \left(\mathrm{i} \omega \frac{y l}{v}\right)$

This expression reveals that the quasi-static value of the road profile experienced by the vehicle axles decreases as the vehicle speed increases, while the frequency content increases. Using Eqs. (7) and (9), the contribution of all axles to a single axle load can be represented by a single 


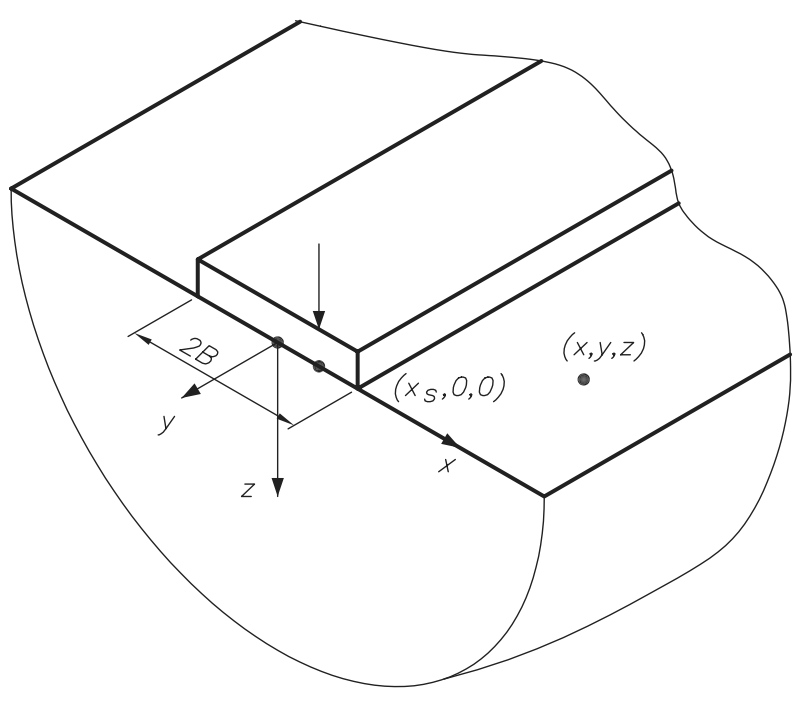

Fig. 2. The road-soil interaction problem.

$\operatorname{FRF} \hat{h}_{f_{k} u}(\omega)$ :

$$
\begin{aligned}
\hat{g}_{k}(\omega) & =\frac{1}{v} \tilde{u}_{\mathrm{w} / \mathrm{r}}\left(-\frac{\omega}{v}\right) \sum_{l=1}^{n} \hat{h}_{f_{k} u_{l}}(\omega) \exp \left(\mathrm{i} \omega \frac{y l}{v}\right) \\
& =\frac{1}{v} \tilde{u}_{w / r}\left(-\frac{\omega}{v}\right) \hat{h}_{f_{k} u}(\omega)
\end{aligned}
$$

This equation shows that the phase lag between the road profile inputs for the vehicle axles diminishes for increasing vehicle speed.

\section{The road-soil transfer function}

The road-soil transfer function $\mathbf{h}_{\mathrm{z}}(x, y, z, t)$ represents the road or soil displacements due to a vertical impulse load on the road. Its calculation is based on a dynamic substructuring method that accounts for dynamic interaction between the road and the soil (Fig. 2). This procedure has been proposed by Clouteau et al. [8] and is briefly recapitulated here.

An analytical beam model is used for the road and a boundary element formulation, based on the Green's functions of a horizontally layered halfspace, is used for the soil. The solution of two subproblems is needed. First, the soil tractions at the road-soil interface are calculated for a Dirac impulse applied in $\left(x_{S}, 0,0\right)$ at time $t=0$. The displacements at an arbitrary location $(x, y, z)$ at time $t$ are subsequently calculated from these soil tractions, resulting in the transfer function $\mathbf{h}_{z}(x, y, z, t)$.

\subsection{The road-soil interaction problem}

The road is assumed to be invariant with respect to the longitudinal direction $y$. It is further assumed that its crosssection is rigid. Therefore, the vertical road displacements $u_{r z}(x, y, t)$ are independent of the vertical coordinate $z$ and can be written in function of the vertical translation $u_{r z}(y, t)$ of the cross-section's centre of gravity and the rotation $\beta_{r y}(y, t)$ about this centre:

$u_{r z}(x, y, t)=u_{r z}(y, t)+x \beta_{r y}(y, t)=\boldsymbol{\phi}_{r}(x) \boldsymbol{\alpha}_{r}(y, t)$

The displacement modes of the rigid cross section are collected in a vector $\boldsymbol{\phi}_{r}=\{1 x\}^{\mathrm{T}}$, while the vector $\boldsymbol{\alpha}_{r}$ collects the displacement $u_{r z}$ and the rotation $\beta_{r y}$. The latter can be interpreted as unknown participation factors on the deformation modes of the rigid cross section.

The foregoing kinematical assumptions immediately result in the following equilibrium equations for the road:

$$
\begin{aligned}
& +E I_{x} \frac{\partial^{4} u_{r z}}{\partial y^{4}}+\rho A \frac{\partial^{2} u_{r z}}{\partial t^{2}}=f_{r z}^{e}+\delta\left(x-x_{S}\right) \delta(y) \delta(z) \delta(t) \\
& -G C \frac{\partial^{2} \beta_{r y}}{\partial y^{2}}+\rho I_{p} \frac{\partial^{2} \beta_{r y}}{\partial t^{2}}=m_{r y}^{e}+x_{S} \delta\left(x-x_{S}\right) \delta(y) \delta(z) \delta(t)
\end{aligned}
$$

These equations govern the longitudinal bending and torsional deformation of the road in function of the translation $u_{r z}$ and the rotation $\beta_{r y}$, respectively. $A$ is the road's cross section, $I_{x}$ the moment of inertia with respect to $x, C$ the torsional moment of inertia and $I_{\mathrm{p}}$ the polar moment of inertia; $E$ is the Young's modulus, $G$ the shear modulus and $\rho$ the density of the road. The vertical force per unit length $f_{r z}^{e}$ and the torsional moment per unit length $m_{r y}^{e}$ in the righthand side of Eqs. (12) and (13) are the forces exerted by the soil on the road along the interface $\Sigma_{r s}$. The other terms in the right hand side represent a Dirac load applied in a point $\left(x_{S}, 0,0\right)$ at time $t=0$.

A double forward Fourier transformation is performed to transform the time $t$ to the circular frequency $\omega$ and the longitudinal coordinate $y$ to the horizontal wavenumber $k_{y}$. The latter is allowed as the road and the soil are invariant in the $y$-direction. The displacement decomposition (11) for the vertical road displacements becomes:

$\tilde{u}_{r z}\left(x, k_{y}, \omega\right)=\tilde{u}_{r z}\left(k_{y}, \omega\right)+x \tilde{\beta}_{r y}\left(k_{y}, \omega\right)=\phi_{r}(x) \tilde{\alpha}_{r}\left(k_{y}, \omega\right)$

In the following, it is understood that a tilde above a variable denotes its representation in the frequency-wavenumber domain so that the arguments $k_{y}$ and $\omega$ can be omitted. The equilibrium Eqs. (12) and (13) become:

$$
\begin{aligned}
& \left(\left[\begin{array}{ll}
E I_{x} k_{y}^{4} & 0 \\
0 & G C k_{y}^{2}
\end{array}\right]-\omega^{2}\left[\begin{array}{ll}
\rho A & 0 \\
0 & \rho I_{p}
\end{array}\right]\right)\left\{\begin{array}{c}
\tilde{u}_{r z} \\
\tilde{\beta}_{r y}
\end{array}\right\} \\
& =\left\{\begin{array}{c}
\tilde{f}_{r z}^{e} \\
\tilde{m}_{r y}^{e}
\end{array}\right\}+\left\{\begin{array}{l}
1 \\
x_{S}
\end{array}\right\}
\end{aligned}
$$

These equations can alternatively be written in matrixvector notation:

$\left(\tilde{\mathbf{K}}_{r}-\omega^{2} \tilde{\mathbf{M}}_{r}\right) \tilde{\boldsymbol{\alpha}}_{r}=\tilde{\mathbf{f}}_{r}+\tilde{\mathbf{f}}_{r}^{\delta}$

with $\tilde{\mathbf{K}}_{r}$ the stiffness matrix, $\tilde{\mathbf{M}}_{r}$ the mass matrix and $\tilde{\mathbf{f}}_{r}^{\delta}$ the 
force vector related to the Dirac load. The vector $\tilde{\mathbf{f}}_{r}$ follows from the equilibrium at the road-soil interface $\Sigma_{r s}$ :

$\tilde{\mathbf{f}}_{r}=-\int_{\Sigma_{r s}} \boldsymbol{\phi}_{r} \tilde{t}_{s z}\left(\tilde{\mathbf{u}}_{s}\right) \mathrm{d} \Gamma$

where $\tilde{t}_{s z}\left(\tilde{\mathbf{u}}_{s}\right)$ is the frequency-wavenumber representation of $t_{s z}\left(\mathbf{u}_{s}\right)$, the vertical component of the soil tractions $\mathbf{t}_{s}=$ $\sigma_{s} \mathbf{n}$ on a boundary with a unit outward normal $\mathbf{n}$ for a displacement field $\mathbf{u}_{s}$.

In the frequency-wavenumber domain, the displacements in the horizontally layered soil are decomposed on the basis of the scattered elastodynamic wave fields, radiated by the bending and torsional modes of the road:

$\tilde{\mathbf{u}}_{s}(x, z)=\tilde{\boldsymbol{\phi}}_{s}(x, z) \tilde{\boldsymbol{\alpha}}_{s}$

The matrix $\tilde{\phi}_{s}$ collects the scattered wave fields in the soil, while the vector $\tilde{\alpha}_{s}$ collects the modal participation factors.

The following welded boundary conditions are applied on the interface $\Sigma_{r s}$ :

$\tilde{\mathbf{u}}_{r}(x)=\tilde{\mathbf{u}}_{s}(x, z=0)$

The vertical forces $\tilde{\mathbf{f}}_{r}^{\delta}$ on the road will generally cause both horizontal and vertical tractions at the road-soil interface. Only the vertical tractions have a non-zero resultant. When the loaded area is small compared to the wavelength in the soil, it can be assumed that the horizontal tractions have a small influence on the free field displacements. Therefore, no restrictions are imposed on the displacements in the $x$ and $y$-direction so that the following continuity condition prevails for the vertical displacement components:

$\tilde{u}_{r z}(x)=\tilde{u}_{s z}(x, z=0)$

These relaxed boundary conditions imply that the influence of the horizontal tractions is neglected in the following.

The application of the displacement decompositions (14) and (18) to the relaxed boundary condition (20) results in:

$\boldsymbol{\phi}_{r}(x) \tilde{\boldsymbol{\alpha}}_{r}=\tilde{\boldsymbol{\phi}}_{s z}(x, z=0) \tilde{\boldsymbol{\alpha}}_{s}$

In the following, the case will be considered where, for each frequency $\omega$ and wavenumber $k_{y}$, the scattered wave field $\tilde{\boldsymbol{\phi}}_{s z}(x, z=0)$ at the road-soil interface $\Sigma_{r s}$ equals the road displacement modes $\boldsymbol{\phi}_{r}(x)$, so that:

$\tilde{\boldsymbol{\alpha}}_{r}=\tilde{\boldsymbol{\alpha}}_{s}$

Therefore, the subscript $r$ or $s$ in the participation factor $\tilde{\boldsymbol{\alpha}}$ can be omitted.

Using the displacement decomposition (18) together with the result of Eq. (22), the force vector (17) can be elaborated as:

$\tilde{\mathbf{f}}_{r}=-\int_{\Sigma_{r s}} \boldsymbol{\phi}_{r} \tilde{t}_{s z}\left(\tilde{\boldsymbol{\phi}}_{s}\right) \tilde{\boldsymbol{\alpha}} \mathrm{d} \Gamma$

The equilibrium equation (16) becomes:

$\left[\tilde{\mathbf{K}}_{r}-\omega^{2} \tilde{\mathbf{M}}_{r}+\int_{\Sigma_{r s}} \boldsymbol{\phi}_{r} \tilde{t}_{s z}\left(\boldsymbol{\phi}_{s}\right) \mathrm{d} \Gamma\right] \tilde{\boldsymbol{\alpha}}=\tilde{\mathbf{f}}_{r}^{\delta}$
The solution of this system of equations gives the complex participation factors $\tilde{\boldsymbol{\alpha}}$ of the torsional and bending modes of the road. The terms on the left hand side correspond to the internal and inertial forces of the road and the impedance of the soil, while the terms on the right hand side correspond to the external load. From these participation factors, the soil tractions at the road-soil interface can be calculated as follows:

$\tilde{t}_{s z}(x, z=0)=\tilde{t}_{s z}\left(\tilde{\boldsymbol{\phi}}_{s}\right)(x, z=0) \tilde{\boldsymbol{\alpha}}$

\subsection{Boundary element method for the soil}

A boundary element method is used to calculate the transformed soil tractions $\tilde{\mathbf{t}}_{s}\left(\tilde{\boldsymbol{\phi}}_{s}\right)$ at the soil-road interface for the scattered wave fields $\tilde{\boldsymbol{\phi}}_{s}$ originating from the bending or torsional modes of the road. The boundary element formulation is based on integral equations, resulting from the application of the Betti-Rayleigh reciprocity theorem in the frequency-wavenumber domain:

$\tilde{\mathbf{u}}_{s}\left(\xi_{1}, \xi_{3}\right)=\int_{\sum_{r s}} \tilde{\mathbf{u}}^{\mathrm{G}}(x, z) \tilde{\mathbf{t}}_{s}(x, z) \mathrm{d} \Gamma-\int_{\sum_{r s}} \tilde{\mathbf{t}}^{\mathrm{G}}(x, z) \tilde{\mathbf{u}}_{s}(x, z) \mathrm{d} \Gamma$

where $\tilde{\mathbf{u}}^{\mathrm{G}}(x, z)$ and $\tilde{\mathbf{t}}^{\mathrm{G}}(x, z)$ are the representations of the 3 by 3 Green's displacement and traction tensors $\mathbf{u}^{\mathrm{G}}(x, y, z, t)$ and $\mathbf{t}^{\mathrm{G}}(x, y, z, t)$ in the frequency-wavenumber domain [11]. These Green's tensors represent the fundamental solutions of a horizontally layered halfspace in a point $\mathbf{x}$ when a Dirac load in space and time is applied in a point $\boldsymbol{\xi} 1$ in one of the coordinate directions [29].

As the road is located at the soil's surface $\Sigma_{r s}$, it is understood that all functions in the integrands of Eq. (26) are evaluated for $z=0$; the Green's tensor $\tilde{\mathbf{t}}^{\mathrm{G}}(x, z)$ is therefore zero. Furthermore, the geometry is invariant in the $x$-direction and the Green's function only depends on $\xi_{1}-x$ for a source and receiver located at the surface $\left(\xi_{3}=0\right.$ and $z=$ 0). Eq. (26) simplifies to:

$\tilde{\mathbf{u}}_{s}\left(\xi_{1}, \xi_{3}=0\right)=\int_{\sum_{r s}} \tilde{\mathbf{u}}^{\mathrm{G}}\left(x-\xi_{1}, z=0\right) \tilde{\mathbf{t}}_{s}(x, z=0) \mathrm{d} \Gamma$

where $\tilde{\mathbf{u}}^{\mathrm{G}}\left(x-\xi_{1}, \xi_{3}=0\right)$ represents the fundamental solution for a source at the origin. As only continuity of the vertical displacement $\tilde{u}_{s z}\left(\xi_{1}, \xi_{3}=0\right)$ is imposed, a single equation remains:

$\tilde{u}_{s z}\left(\xi_{1}, \xi_{3}=0\right)=\int_{\sum_{r s}} \tilde{u}_{z z}^{\mathrm{G}}\left(x-\xi_{1}, z=0\right) \tilde{t}_{s z}(x, z=0) \mathrm{d} \Gamma$

and only one element $\tilde{u}_{z z}^{\mathrm{G}}(x, z)$ of the Green's displacement tensor is needed.

In the frequency-wavenumber domain, the Green's function $\tilde{u}_{z z}^{\mathrm{G}}\left(x, k_{y}, z, \omega\right)$ is calculated as the following inverse 
Fourier transformation:

$\tilde{u}_{z z}^{\mathrm{G}}\left(x, k_{y}, z, \omega\right)=\frac{1}{2 \pi} \int_{-\infty}^{+\infty} \tilde{\tilde{u}}_{z z}^{\mathrm{G}}\left(k_{x}, k_{y}, z, \omega\right) \exp \left(-\mathrm{i} k_{x} x\right) \mathrm{d} k_{x}$

where the Green's function $\tilde{\tilde{u}}_{z z}^{\mathrm{G}}\left(k_{x}, k_{y}, z, \omega\right)$ can be written in terms of the axisymmetric Green's function $\tilde{u}_{z z}^{\mathrm{Gax}}\left(k_{r}, z, \omega\right)$ :

$\tilde{\tilde{u}}_{z z}^{\mathrm{G}}\left(k_{x}, k_{y}, z, \omega\right)=2 \pi \tilde{u}_{z z}^{\mathrm{Gax}}\left(\sqrt{k_{x}^{2}+k_{y}^{2}}, z, \omega\right)$

The Green's function $\tilde{u}_{z z}^{\mathrm{Gax}}\left(k_{r}, z, \omega\right)$ is calculated with a direct stiffness method for a horizontally layered soil $[12,13,24]$. The correspondence principle is applied to the Lamé coefficients to represent hysteretic material damping in the soil. This moves the poles of the axisymmetric Green's function in Eq. (30) into the complex plane, allowing for numerical evaluation of the inverse wavenumber integral (29).

A collocation method with constant elements is used for the calculation of the soil tractions, which are consequently interpolated from the values at the elements' centres of gravity by means of global shape functions $N_{l}(x)$ that are equal to 1 on the element $l$ considered and zero elsewhere:

$\tilde{t}_{s z}(x, z=0)=\sum_{l=1}^{n} \tilde{t}_{s z l} N_{l}(x)$

Eq. (28) can now be rewritten for each centre of gravity $\xi_{k}$ by means of the discretization introduced in Eq. (31):

$\tilde{u}_{s z}\left(\xi_{k}, \xi_{3}=0\right)=\sum_{l=1}^{n} \tilde{t}_{s z l} \int_{\sum_{r s}} \tilde{u}_{z z}^{\mathrm{G}}\left(x-\xi_{k}, z=0\right) N_{l}(x) \mathrm{d} \Gamma$

This results in the following system of $n$ equations and $n$ unknowns:

$\mathbf{G} \tilde{\mathbf{t}}_{s z}=\tilde{\mathbf{u}}_{s z}$

where the coefficients of the matrix $\mathbf{G}$ are calculated through an integration of the Green's functions. This system of equations allows to calculate the unknown soil tractions $\tilde{\mathbf{t}}_{s z}$ for the scattered wave fields $\tilde{\mathbf{u}}_{s z}$, originating from the bending and torsional deformations of the road, for which $\tilde{u}_{s z}\left(\xi_{k}, \xi_{3}=0\right)=1$ and $\tilde{u}_{s z}\left(\xi_{k}, \xi_{3}=0\right)=\xi_{k}$, respectively.

\subsection{The transfer function between the road and the soil}

The reciprocity theorem (28) is used once again to calculate the road-soil transfer function $\tilde{\mathbf{h}}_{z}\left(\xi_{1}, \xi_{3}\right)$, which represents the soil displacements in the frequency-wavenumber domain due to a vertical impulse loading on the road:

$\tilde{\mathbf{h}}_{z}\left(\xi_{1}, \xi_{3}\right)=\int_{\sum_{r s}} \tilde{\mathbf{u}}_{z}^{\mathrm{G}}\left(x-\xi_{1}, z=0\right) \tilde{t}_{s z}(x, z=0) \mathrm{d} \Gamma$

where $\tilde{t}_{s z}(x, z=0)$ are the vertical soil tractions at the interface and $\tilde{\mathbf{u}}_{z}^{\mathrm{G}}(x, z)$ represents the Green's tensor of a layered halfspace due to a vertical source in $\left(0,0, \xi_{3}\right)$.

When only the vertical displacements are considered, the following equation prevails:

$\tilde{h}_{z z}\left(\xi_{1}, \xi_{3}\right)=\int_{\sum_{r s}} \tilde{u}_{z z}^{\mathrm{G}}\left(x-\xi_{1}, z=0\right) \tilde{t}_{s z}(x, z=0) \mathrm{d} \Gamma$

\section{The response to the moving dynamic axle loads}

The dynamic Betti-Rayleigh reciprocal theorem is used to calculate the response of the soil or the road. When the problem geometry is assumed to be invariant with respect to $y$, the displacements are calculated as the following convolution integral of the vertical axle loads $g_{k}(t)$ and the transfer function $\mathbf{h}_{z}(x, y, z, t)$ between the source and the receiver:

$\mathbf{u}(x, y, z, t)=\sum_{k=1}^{n} \int_{+\infty}^{t} \mathbf{h}_{z}\left(x, y-y_{k}-v \tau, z, t-\tau\right) g_{k}(\tau) \mathrm{d} \tau$

The representation of this solution in the frequency-wavenumber domain is:

$$
\begin{aligned}
\tilde{\mathbf{u}}\left(x, k_{y}, z, \omega\right)= & \int_{-\infty}^{+\infty} \int_{-\infty}^{+\infty} u_{z}(x, y, z, t) \exp (-\mathrm{i} \omega t) \\
& \times \exp \left(+i k_{y} y\right) \mathrm{d} t \mathrm{~d} y \\
= & \tilde{\mathbf{h}}_{z}\left(x, k_{y}, z, \omega\right) \sum_{k=1}^{n} \hat{g}_{k}\left(\omega-k_{y} v\right) \exp \left(\mathrm{i} k_{y} y_{k}\right)
\end{aligned}
$$

Note that a frequency shift $k_{y} v$ is applied to the argument of the interaction force $\hat{g}_{k}\left(\omega-k_{y} v\right)$, where $\omega$ is the frequency at the receiver, while $\omega-k_{y} v$ corresponds to the frequency emitted at the source. The latter will be denoted as $\tilde{\omega}$ in the following. The displacements $\hat{\mathbf{u}}(x, y, z, \omega)$ in the frequency domain are found as the inverse Fourier transform of Eq. (37):

$$
\begin{aligned}
\hat{\mathbf{u}}(x, y, z, \omega)= & \frac{1}{2 \pi} \int_{-\infty}^{+\infty} \tilde{u}_{z}\left(x, k_{y}, z, \omega\right) \exp \left(-\mathrm{i} k_{y} y\right) \mathrm{d} k_{y} \\
= & \frac{1}{2 \pi} \int_{-\infty}^{+\infty} \tilde{\mathbf{h}}_{z}\left(x, k_{y}, z, \omega\right) \sum_{k=1}^{n} \hat{g}_{k}\left(\omega-k_{y} v\right) \\
& \times \exp \left[-\mathrm{i} k_{y}\left(y-y_{k}\right)\right] \mathrm{d} k_{y}
\end{aligned}
$$

A change of variables according to $k_{y}=(\omega-\tilde{\omega}) / \nu$ moves the frequency shift from the axle load to the transfer function:

$$
\begin{aligned}
\hat{\mathbf{u}}(x, y, z, \omega)= & \frac{1}{2 \pi v} \int_{-\infty}^{+\infty} \tilde{\mathbf{h}}_{z}\left(x, \frac{\omega-\tilde{\omega}}{v}, z, \omega\right) \sum_{k=1}^{n} \hat{g}_{k}(\tilde{\omega}) \\
& \times \exp \left[-\mathrm{i}\left(\frac{\omega-\tilde{\omega}}{v}\right)\left(y-y_{k}\right)\right] \mathrm{d} \tilde{\omega}
\end{aligned}
$$


Eq. (39) can be fully elaborated as follows:

$$
\begin{aligned}
\hat{\mathbf{u}}(x, y, z, \omega)= & \frac{1}{2 \pi v} \int_{-\infty}^{+\infty} \hat{\mathbf{h}}_{z}\left(x, \frac{\omega-\tilde{\omega}}{v}, z, \omega\right) \frac{1}{v} \tilde{u}_{w / r}\left(-\frac{\tilde{\omega}}{v}\right) \\
& \times \sum_{k=1}^{n} \sum_{l=1}^{n} \hat{h}_{f_{k} u_{l}}(\tilde{\omega}) \exp \left(\mathrm{i} \tilde{\omega} \frac{y l}{v}\right) \\
& \times \exp \left[-\mathrm{i}\left(\frac{\omega-\tilde{\omega}}{v}\right)\left(y-y_{k}\right)\right] \mathrm{d} \tilde{\omega}
\end{aligned}
$$

and illustrates that traffic-induced vibrations are caused by dynamic vehicle loads that cause wave propagation in the soil. The dynamic axle loads result from the interaction of the vehicle and the road unevenness. The transfer function accounts for dynamic road-soil interaction and couples the source to the receiver.

When the moving source is a single harmonic force $g(t)=\exp \left(+\mathrm{i} \tilde{\omega}_{0} t\right)$, the frequency content $\hat{g}(\tilde{\omega})=2 \pi \delta(\tilde{\omega}-$ $\tilde{\omega}_{0}$ ) and Eq. (39) becomes:

$\hat{\mathbf{u}}(x, y, z, \omega)=\frac{1}{v} \tilde{\mathbf{h}}_{z}\left(x, \frac{\omega-\omega_{0}}{v}, z, \omega\right) \exp \left[-\mathrm{i}\left(\frac{\omega-\tilde{\omega}_{0}}{v}\right) y\right]$

We consider the case where the speed $v$ of the source is lower than the Rayleigh wave velocity $C_{r}$. When the source approaches the receiver, only waves travelling in the positive $y$-direction contribute to the response. As the phase velocity $C_{r y}=\omega / k_{y}$ is larger than $C_{r}$, where the wave number $k_{y}$ is equal to $\left(\omega-\omega_{0}\right) / v$, the Rayleigh wave contribution to the response is situated at frequencies $\omega$ between $\tilde{\omega}$ and $\tilde{\omega} /\left[1-\left(v / C_{r}\right)\right]$; this frequency interval becomes larger for increasing speed of the source with respect to $C_{r}$. When the source is receding from the receiver, it can be demonstrated that the Rayleigh wave contribution is situated between $\tilde{\omega} /\left[1+\left(v / C_{r}\right)\right]$ and $\tilde{\omega}$. This phenomenon is known as the Doppler effect. Analogous conclusions can be drawn for shear and dilatational waves.

The vertical displacements in the time domain are finally obtained by the evaluation of the inverse Fourier transform:

$\mathbf{u}(x, y, z, t)=\frac{1}{2 \pi} \int_{-\infty}^{+\infty} \hat{\mathbf{u}}(x, y, z, \omega) \exp (\mathrm{i} \omega t) \mathrm{d} \omega$

\section{Validation}

In this section, the foregoing theoretical developments are validated by means of analytical solutions for the response at the surface of a homogeneous halfspace due to a moving vertical point load. Mandel and Avramesco [31] have calculated the response for a stationary moving load by means of a Galilean transformation to a moving coordinate system.

In Eq. (4) of the paper by Mandel and Avramesco [31], the analytical solution for the vertical displacement for a stationary load is given for a material without hysteretic damping. This solution will be compared to numerical results obtained with Eq. (39). For a stationary load, the time-dependent part of the moving load $g(t)=Q_{0}$. Its Fourier transform equals $\hat{g}(\omega)=2 \pi Q_{0} \delta(\omega)$ and the soil response follows from Eq. (39):

$\hat{u}_{z}(x, y, z, \omega)=\frac{Q_{0}}{v} \tilde{h}_{z z}\left(x, \frac{\omega}{v}, z, \omega\right) \exp \left[-\mathrm{i}\left(\frac{\omega}{v}\right) y\right]$

First, the case is considered where no road is present and the load is immediately applied to the soil. The vertical component $\tilde{h}_{z z}\left(x, k_{y}, z, \omega\right)$ of the transfer function in Eq. (43) is then equal to the Green's function $\tilde{u}_{z z}^{\mathrm{G}}\left(x, k_{y}, z, \omega\right)$ of the soil. In the following calculations, the soil has a Young's modulus $E=$ $1.08 \times 10^{8} \mathrm{~N} / \mathrm{m}^{2}$, a Poisson's ratio $\nu=0.25$ and a density $\rho=1800 \mathrm{~kg} / \mathrm{m}^{3}$. The shear wave velocity $C_{\mathrm{s}}=154.9 \mathrm{~m} / \mathrm{s}$ and the dilatational wave velocity $C_{\mathrm{p}}=268.3 \mathrm{~m} / \mathrm{s}$. A small hysteretic material damping ratio $\beta=0.005$ in shear and volumetric deformation is used in this example. This low value does not correspond to real soil behaviour, but removes the surface wave pole from the real axis; it is low enough to limit the influence of material damping on the computational results. Fig. 3 shows the time history of the soil's response at a distance of $24 \mathrm{~m}$ from the source line, for a constant load $Q_{0}=1$ and a speed $v=100 \mathrm{~m} / \mathrm{s}$. The underestimation of the response at both small and large times $t$ is caused by the material damping.

Next, the load is applied at the centre of a road on top of the same halfspace and the response is calculated from Eq. (43) with a transfer function $\tilde{h}_{z z}\left(x, k_{y}, z, \omega\right)$ that accounts for the dynamic interaction between the road and the soil. Both a flexible and a rigid road will be considered. In both cases, the road has a width $2 B=1 \mathrm{~m}$, a height $h=0.40 \mathrm{~m}$ and a density $\rho=2000 \mathrm{~kg} / \mathrm{m}^{3}$.

Fig. 4a shows the time history of the response at a distance of $24 \mathrm{~m}$ for the case of a flexible road with a Young's modulus $E=5.44 \times 10^{8} \mathrm{~N} / \mathrm{m}^{2}$. As expected, the small width and the bending stiffness barely influence the response. Therefore, the numerical results agree well with

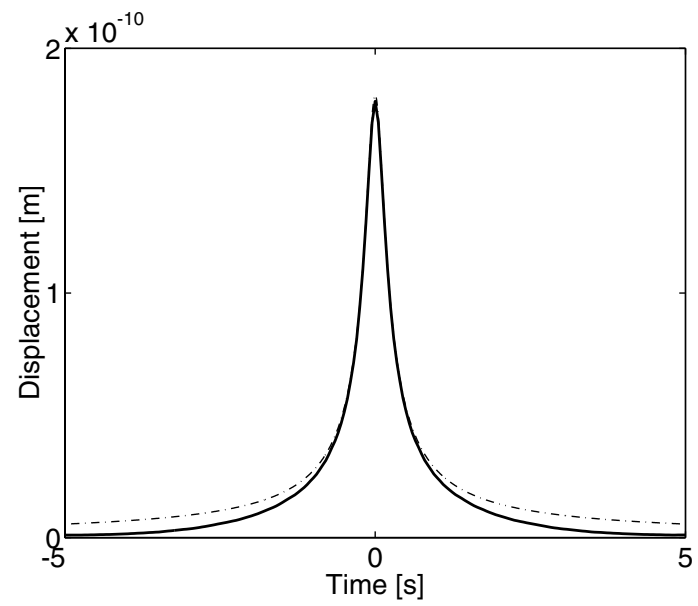

Fig. 3. Time history of the vertical displacement at $24 \mathrm{~m}$ from the source line. The dashed line corresponds to the solution of Mandel and Avramesco, while the solid line corresponds to the numerical results. 


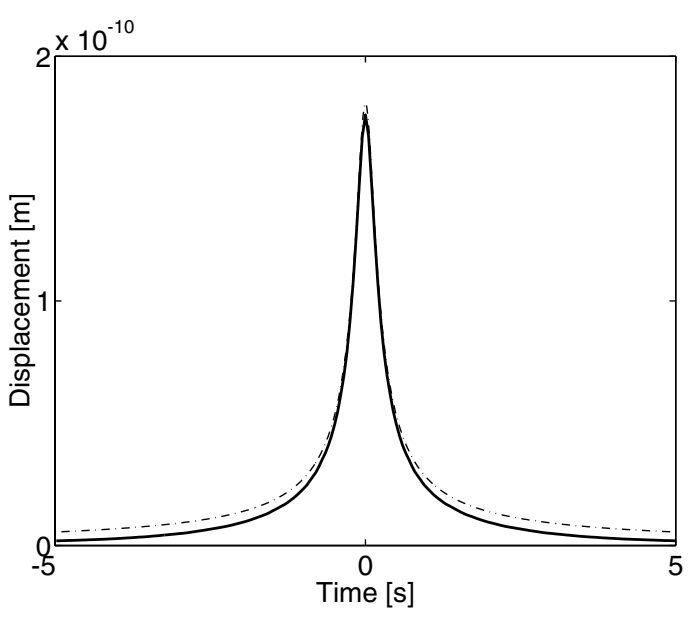

a. $E=5.44 \times 10^{8} \mathrm{~N} / \mathrm{m}^{2}$.

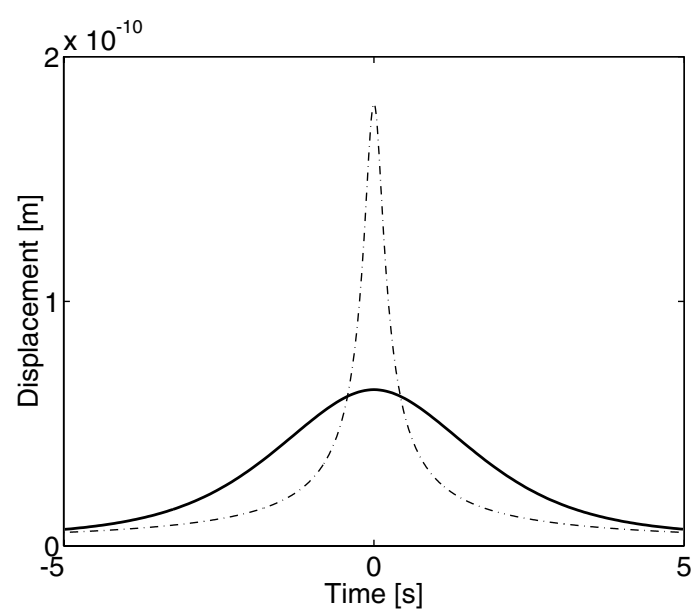

b. $E=5.44 \times 10^{17} \mathrm{~N} / \mathrm{m}^{2}$.

Fig. 4. Time history of the vertical displacement at $24 \mathrm{~m}$ from the source line for a road with a Young's modulus (a) $E=5.44 \times 10^{8} \mathrm{~N} / \mathrm{m}^{2}$ and (b) $E=$ $5.44 \times 10^{7} \mathrm{~N} / \mathrm{m}^{2}$. The dashed line corresponds to the solution of Mandel and Avramesco, while the solid line corresponds to the numerical results.

the analytical results. Fig. 4b shows the time history of the response at a distance of $24 \mathrm{~m}$ for a rigid road with a Young's modulus $E=5.44 \times 10^{17} \mathrm{~N} / \mathrm{m}^{2}$. As expected, the maximum displacement is much smaller.

\section{Numerical example}

\subsection{Problem outline}

The free field vibrations during the passage of a truck on a traffic plateau, located on a road supported by a homogeneous halfspace are calculated (Fig. 5).

The original truck model with 29 DOF is reduced by an Irons-Guyan reduction to an equivalent 4 DOF vehicle model, as shown in Fig. 1, with the following parameters: $m_{b}=13280 \mathrm{~kg}, I_{b}=60397 \mathrm{~kg} \mathrm{~m}^{2}, m_{a 1}=1250 \mathrm{~kg}, m_{a 2}=$ $650 \mathrm{~kg}, l_{1}=-1.775 \mathrm{~m}, l_{2}=+2.225 \mathrm{~m}, \quad k_{p 1}=1.26(1+$ $0.20 i) \times 10^{6} \mathrm{~N} / \mathrm{m}, \quad c_{p 1}=0 \mathrm{Ns} / \mathrm{m}, \quad k_{p 2}=0.66(1+0.80 i) \times$ $10^{6} \mathrm{~N} / \mathrm{m}, \quad c_{p 2}=8000 \mathrm{Ns} / \mathrm{m}, \quad k_{t 1}=2.80 \times 10^{6} \mathrm{~N} / \mathrm{m}, \quad c_{t 1}=$ $4200 \mathrm{Ns} / \mathrm{m}, k_{t 2}=1.40 \times 10^{6} \mathrm{~N} / \mathrm{m}$ and $c_{t 2}=2100 \mathrm{Ns} / \mathrm{m}$.

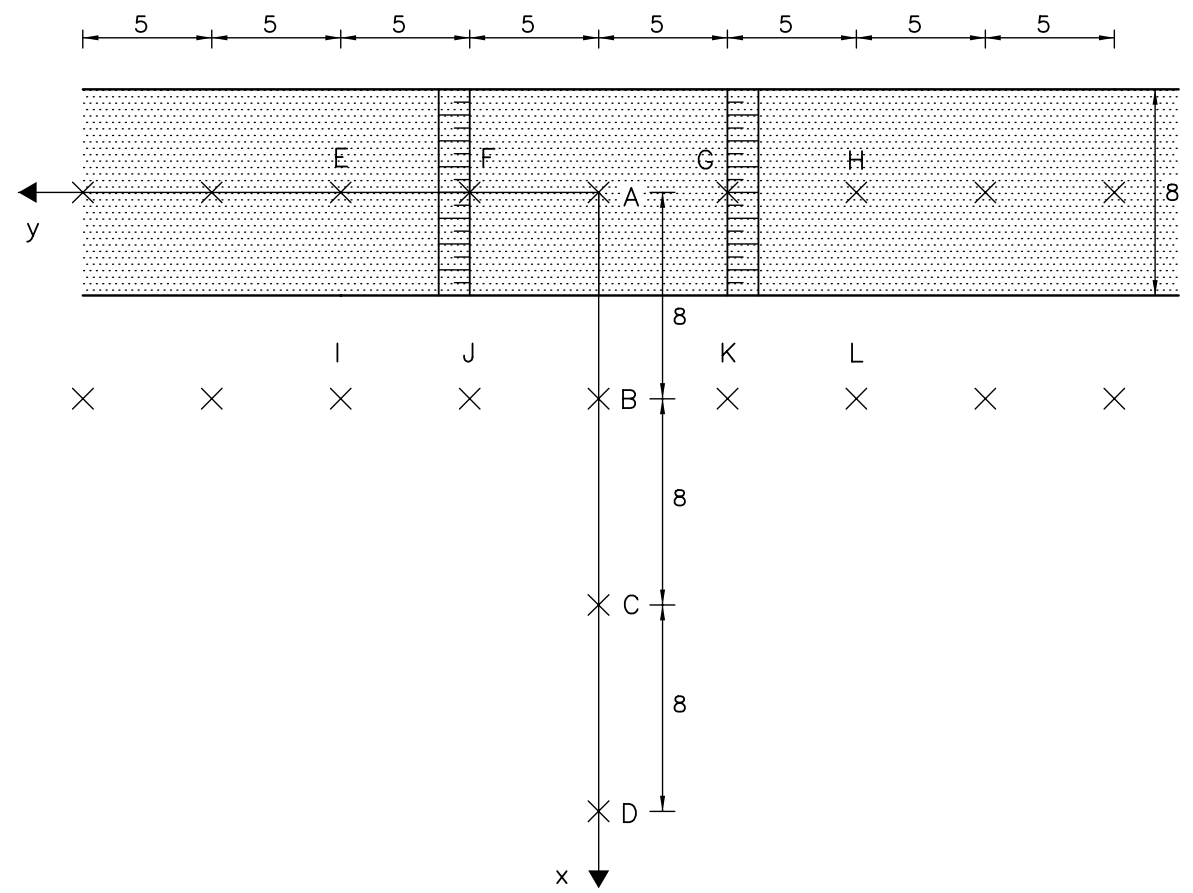

Fig. 5. Problem outline for the passage of a truck on a traffic plateau. 
The road has a width $2 B=8 \mathrm{~m}$, a height $h=0.40 \mathrm{~m}$, a Young's modulus $E=5.44 \times 10^{8} \mathrm{~N} / \mathrm{m}^{2}$, a shear modulus $G=2.10 \times 10^{8} \mathrm{~N} / \mathrm{m}^{2}$ and a density $\rho=2000 \mathrm{~kg} / \mathrm{m}^{3}$.

The soil has a Young's modulus $E=1.08 \times 10^{8} \mathrm{~N} / \mathrm{m}^{2}$, a Poisson's ratio $\nu=1 / 3$, a density $\rho=1800 \mathrm{~kg} / \mathrm{m}^{3}$ and a hysteretic material damping ratio $\beta=0.025$ in shear and volumetric deformation. The shear wave velocity $C_{\mathrm{s}}=150.0 \mathrm{~m} / \mathrm{s}$ and the dilatational wave velocity $C_{\mathrm{p}}=300.0 \mathrm{~m} / \mathrm{s}$.

The vertical free field response will be calculated in a point $A$ on the road, in the points $B, C$ and $D$ in the soil on a line perpendicular to the road, centrally located with respect to the slopes of the traffic plateau, and in the points $I$, $J, K$ and $L$ in the soil on a line parallel to the longitudinal axis of the road (Fig. 5).

\subsection{The road profile}

The longitudinal profile $u_{\mathrm{w} / \mathrm{r}}(y)$ of the traffic plateau is described as [4]:

$u_{\mathrm{w} / \mathrm{r}}(y)= \begin{cases}H & |y|<\frac{L}{2} \\ H\left[1-\cos \left(\frac{2 \pi(|y|-L / 2+l)}{2 l}\right)\right] & \frac{L}{2}<|y|<\frac{L}{2}+l \\ 0 & |y|>\frac{L}{2}+l\end{cases}$

with $H=0.12 \mathrm{~m}$ the height of the plateau, $L=10 \mathrm{~m}$ the length of the top surface and $l=1.20 \mathrm{~m}$ the length of both sinusoidal slopes as shown in Fig. 6a.

The wavenumber domain representation of this road profile can be calculated analytically:

$\tilde{u}_{\mathrm{w} / \mathrm{r}}\left(k_{y}\right)=h(L+l) \operatorname{sinc}\left[\frac{k_{y}(L+l)}{2}\right]\left[\frac{1}{1-\left(k_{y} l / \pi\right)^{2}}\right] \cos \left(\frac{k_{y} l}{2}\right)$

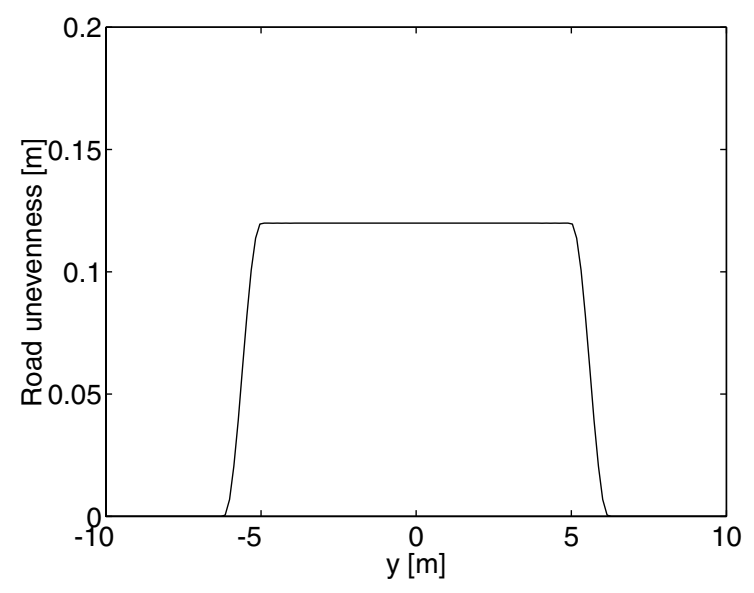

a. $u_{w / r}(y)$.
Fig. $6 \mathrm{~b}$ shows the representation of the road profile in the wavenumber domain. The first factor $h(L+l)$ of Eq. (45) is the quasi-static value; the $\sin c$ function represents a lobed function, with a separation between the lobes that is inversely proportional to the mean length $l+L$ of the plateau. The bracketed term has a pole at $k_{y}= \pm \pi / l$, which is canceled by the cosine function. The product of both terms results in a lobed function, with zeros at wavenumber intervals that are inversely proportional to the length $l$ of the slopes. The latter cannot be distinguished in Fig. 6b.

\subsection{The dynamic axle loads}

The time history of the road profile as experienced by the front axle for a vehicle speed $v=14 \mathrm{~m} / \mathrm{s}$ is shown in Fig. 7a. The spectrum of the road profile is calculated from the wavenumber domain representation in Fig. 6b. As $\tilde{\omega}=$ $-v k_{y}$, the separation between the lobes is proportional to the ratio of the vehicle speed $v$ to the mean length $L+l$ of the plateau. Fig. 7c shows the FRF for the front axle load, which is dominated by the pitch and bounce modes (1.6 and $1.9 \mathrm{~Hz})$ and the axle hop modes $(9.1 \mathrm{~Hz}$ at the front axle and $9.5 \mathrm{~Hz}$ at the rear axle) of the vehicle. According to Eq. (10), the spectrum of the front axle load (Fig. 7e) is obtained as the product of the Fourier transform of the road profile (Fig. 7b) and the vehicle's FRF (Fig. 7c). This spectrum also shows a lobed behaviour and is dominated by the vehicle's pitch and bounce modes. The time history of the front axle load (Fig. 7d) is found by means of an inverse FFT algorithm and clearly shows the impact at the ascending and the descending slope of the traffic plateau. An analogous procedure can be followed for the determination of the rear axle load.

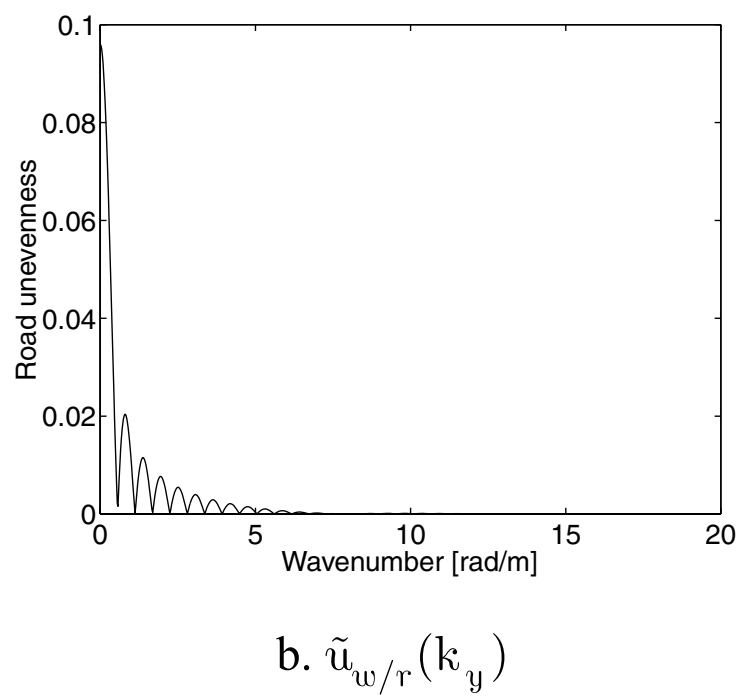

Fig. 6. The longitudinal road profile of a traffic plateau with sinusoidal slopes (a) as a function of the coordinate $y$ along the road and (b) in the wavenumber domain. 


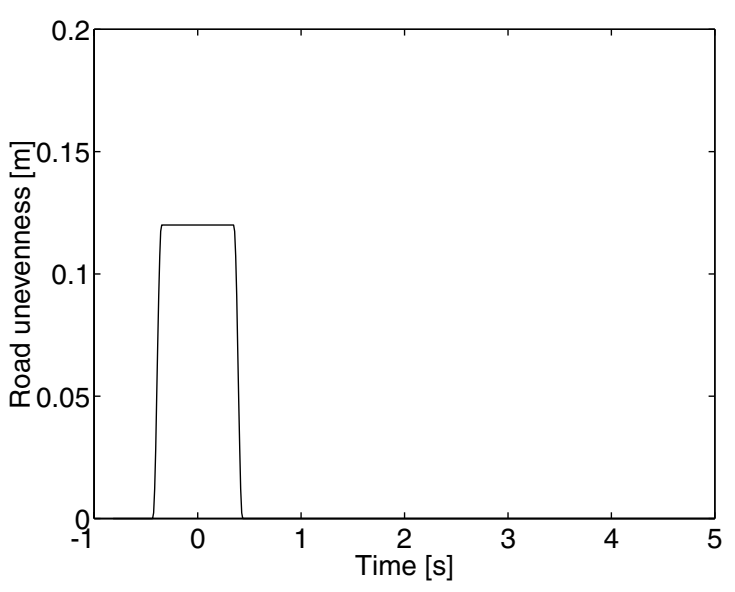

a. $u_{w / r}(t)$.

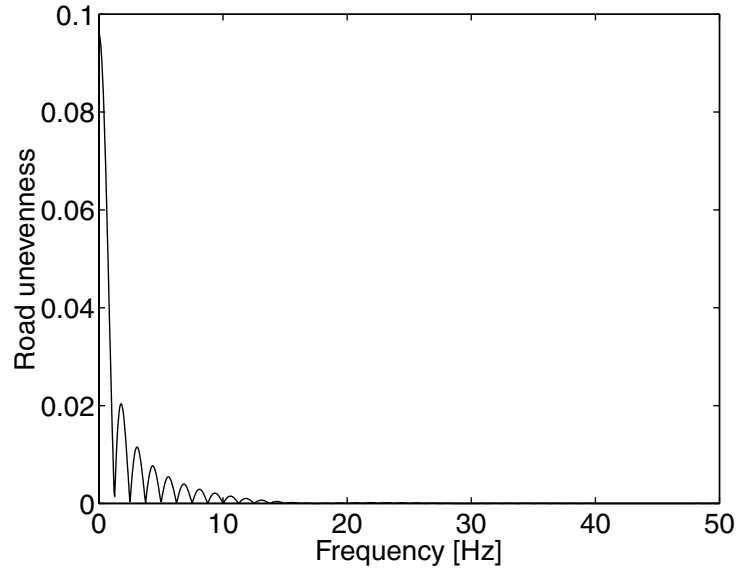

b. $\tilde{u}_{w / r}(w)$.

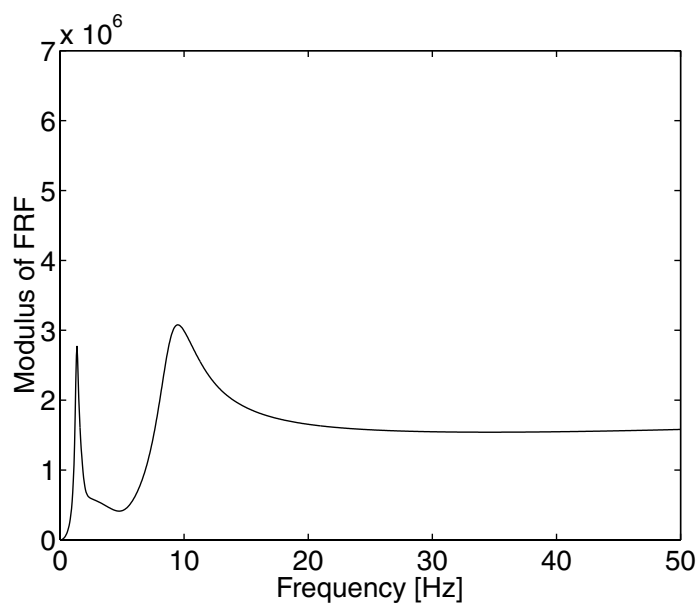

c. $\hat{h}_{f_{2} u}(w)$.

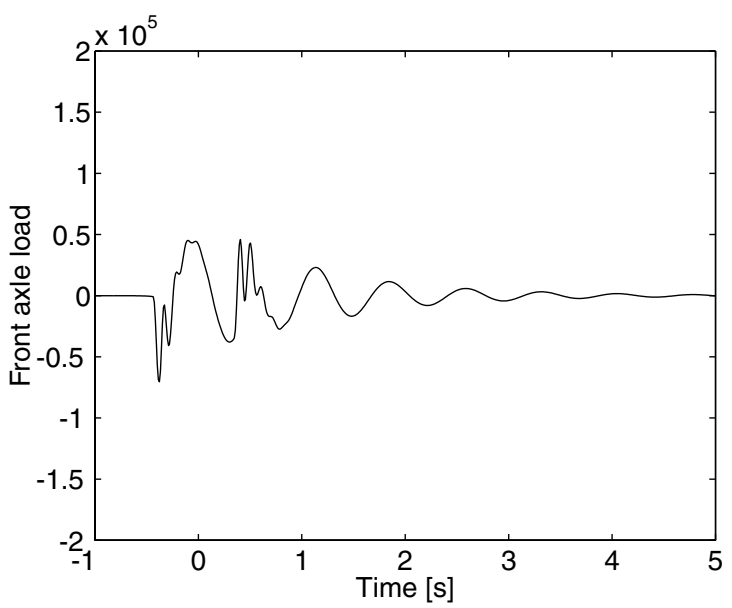

d. $F_{w / r}^{i n t 2}(t)$.

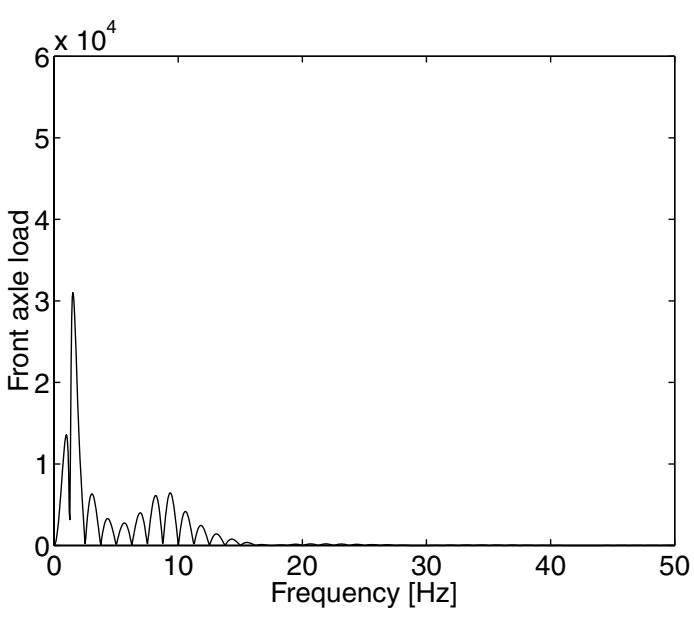

e. $\hat{F}_{w / r}^{i n t 2}(w)$.

Fig. 7. The calculation of the front axle load. 


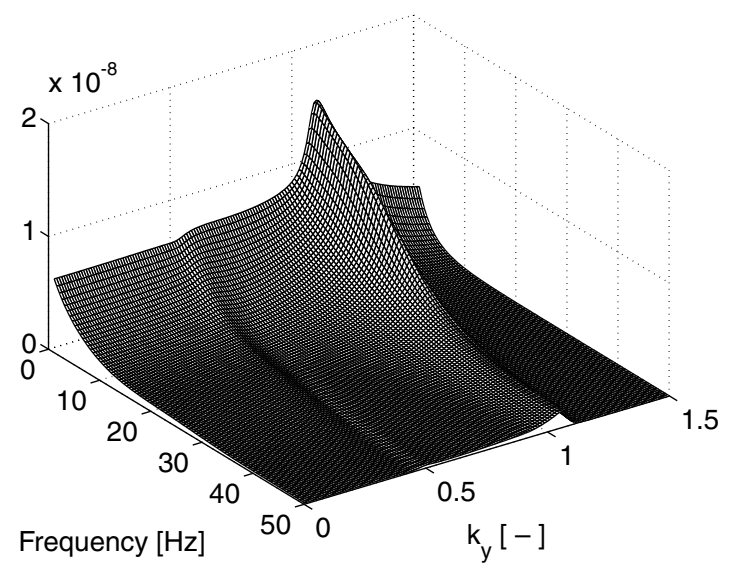

Fig. 8. Modulus of the road-soil transfer function $\tilde{h}_{z z}\left(x, k_{y}, z, \omega\right)$ in the frequency-wavenumber domain for a load at the centre of the road $\left(x_{S}=\right.$ 0 ) and a receiver located at $x=8 \mathrm{~m}$ and $z=0$.

\subsection{The free field response of the road and the soil}

The road-soil transfer function $\tilde{h}_{z z}\left(x, k_{y}, z, \omega\right)$ is calculated in the frequency-wavenumber domain for a load at the centre of the road $\left(x_{S}=0\right)$ and receivers located at the surface $(z=0)$ at $x=0,8,18$ and $24 \mathrm{~m}$. Twenty boundary elements of equal length $(0.40 \mathrm{~m})$ are used for the discretization of the road-soil interface, while the Green's functions are integrated by means of a Gauss-Legendre quadrature method, using four Gaussian points per interval. Fig. 8 shows the modulus of the transfer function $\tilde{h}_{z z}\left(x, k_{y}, z, \omega\right)$ for $x=8 \mathrm{~m}$ as a function of the dimensionless wavenumber $\bar{k}_{y}=k_{y} \omega / C_{\mathrm{s}}$ and the frequency $\omega$. The large peak at $\bar{k}_{y}=1.073$ corresponds to the propagation of Rayleigh waves in the $y$-direction.

Fig. 9 shows the time history and frequency content of the vertical road and soil velocities in the points $A, B, C$ and $D$ on a line perpendicular to the road. The frequency content is calculated according to Eq. (38), while the time history is obtained with an inverse FFT. The spectrum is dominated by both the pitch and bounce modes and the axle hop modes of the vehicle; the lobed behaviour that originates from the frequency content of the road profile is also clearly observable. A comparison of the vibration levels in the points $A$, $B, C$ and $D$ shows that the peak particle velocity (PPV) decreases, while the frequency content of the signal is reduced, for increasing distance to the road. This is due to radiation and material damping in the soil.

Fig. 10 shows the time history and the frequency content of the vertical soil velocities in the points $I, J, K$ and $L$ on a line parallel to the longitudinal axis of the road. These points are located at the same distance to the road as the point $B$ $(x=8 \mathrm{~m})$. Following Eq. (38), the transfer function $\tilde{h}_{z z}(x=$ $\left.8, k_{y}, z=0, \omega\right)$ of Fig. 8 is used to calculate the frequency content of the response. The latter is once again dominated by the pitch and bounce modes and the axle hop modes of the vehicle. The time history clearly shows that the impact at the ascending of the plateau generates the largest vibration levels in the point $J$, while the descending of the plateau generates the largest levels in the point $K$. An analogous observation can be made regarding the vibration levels in the points $I$ and $L$.

\subsection{The influence of the vehicle speed}

As the vehicle speed is one of the most important factors for free field traffic-induced vibrations, the vertical soil velocities in the point $B$ are subsequently calculated for a vehicle speed $v$ equal to $8,12,16$ and $20 \mathrm{~m} / \mathrm{s}$. The left-hand side of Fig. 11 shows the frequency content of the road profile experienced by the vehicle axles. As follows from Eq. (9) the quasi-static value decreases, while the separation between the lobes enlarges as the frequency content shifts to higher frequencies. The right-hand side of Fig. 11 shows the frequency content of the front axle load. Due to the weak coupling between the vehicle axles, the influence of the speed-dependent phase lag in Eq. (10) is small; the variation of the frequency content of the axle loads with the vehicle speed is dominated by $\hat{u}_{\mathrm{w} / \mathrm{r}}^{l}(\omega)$.

The left-hand side of Fig. 12 shows the time history of the soil velocities in the point $B$. As the vehicle speed increases, the time delay between the impact at the ascending and the descending of the plateau decreases and the peak particle velocity (PPV) increases. The right-hand side of Fig. 12 shows the frequency content of the soil velocities in the point $B$. From these figures, it is clear that an increasing vehicle speed shifts the frequency content to the axle hop modes, resulting in a higher PPV. It also follows from Eq. (38) that the frequency content of the axle loads widens for increasing vehicle speeds. This example therefore illustrates that the relationship between vehicle speed and vibration levels is a function of the suspension system and the condition of the road surface, as has also been observed earlier during in situ measurements [1].

\section{Conclusion}

A numerical model has been presented that enables the calculation of free field traffic-induced vibrations. Vehicle transfer functions have been used for the calculation of the dynamic axle loads from the longitudinal road profile and a linear vehicle model. The calculation of the road and soil vibrations is based on an application of the Betti-Rayleigh reciprocity theorem for moving point loads. The main assumptions are the invariance of the road in the longitudinal direction and the rigidity of the road section. Crucial in the mathematical description is the transfer function between the road and the receiver in the free field. Its calculation is based on a dynamic road-soil interaction model.

A numerical example demonstrates the influence of the vehicle speed, the vehicle's transfer functions, the road profile and the dynamic soil characteristics on the frequency content of the response. A comparison of the results obtained at various distances on a line perpendicular to the road shows the decay of the vibrations due to wave 

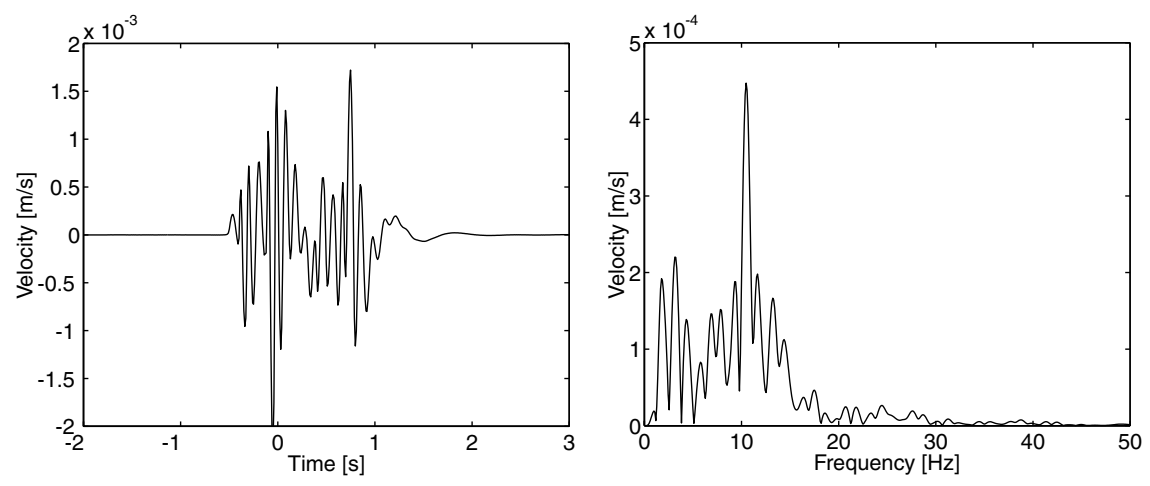

a. $v_{A}(t)$.

b. $\hat{v}_{A}(w)$.
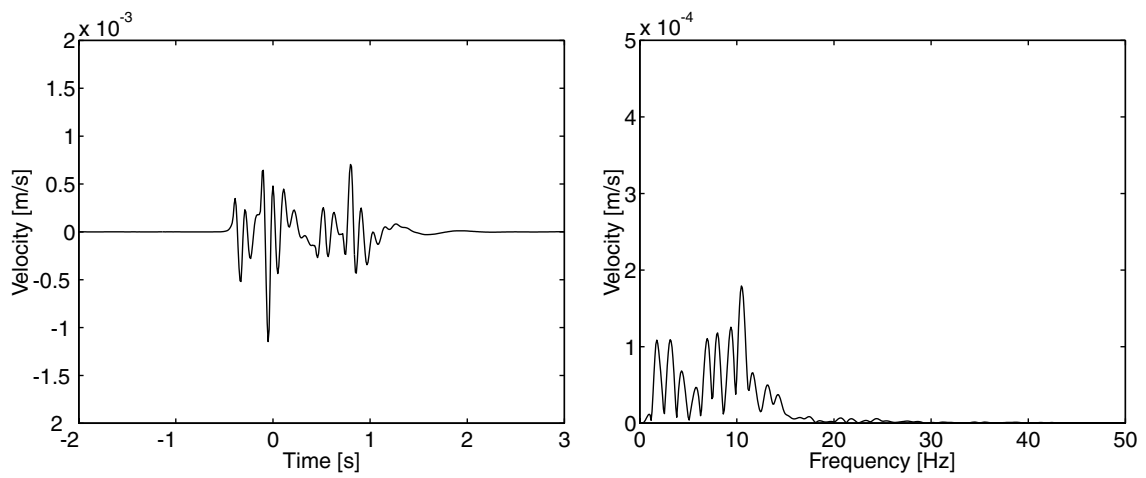

c. $v_{B}(t)$.

d. $\hat{v}_{B}(w)$.
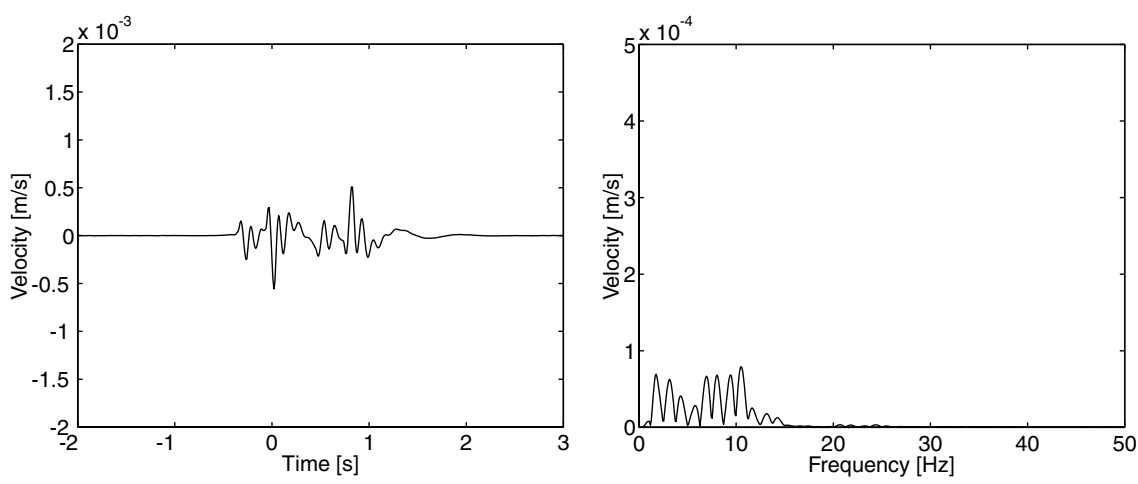

e. $v_{C}(t)$.

f. $\hat{v}_{C}(w)$.
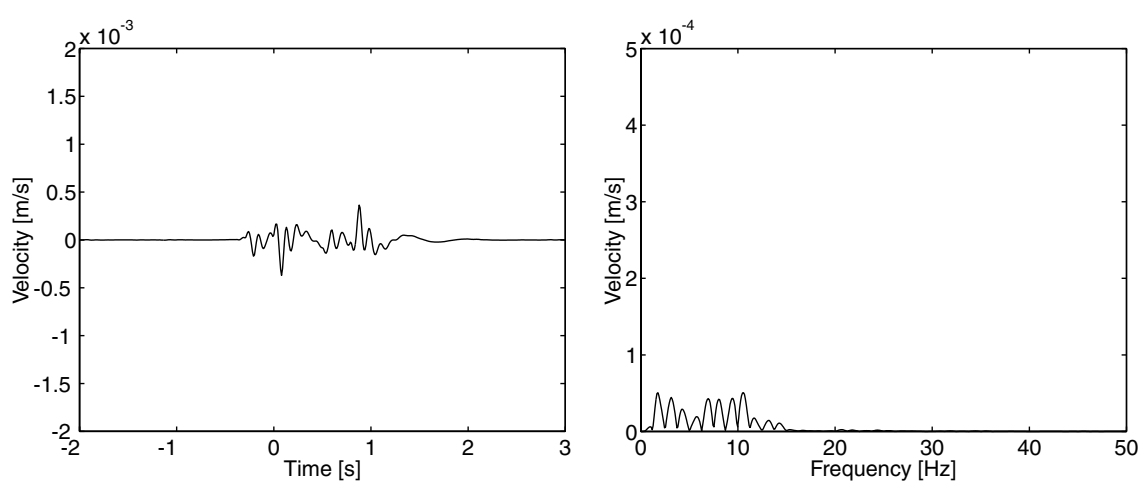

g. $v_{D}(t)$.

h. $\hat{v}_{D}(w)$.

Fig. 9. Time history (left) and frequency content (right) of the vertical velocity in the points $A, B, C$ and $D$ on a line perpendicular to the road. 


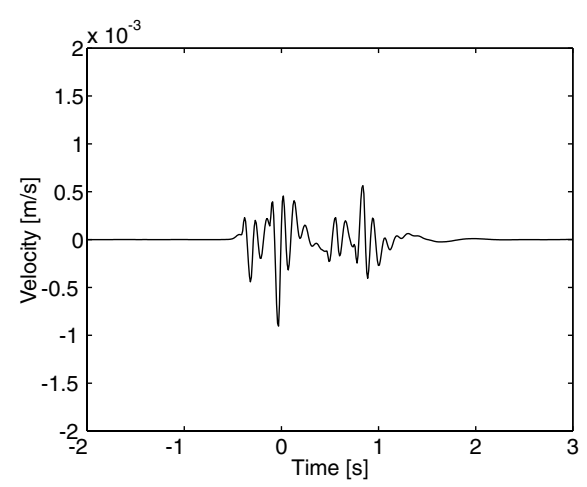

a. $v_{I}(t)$.

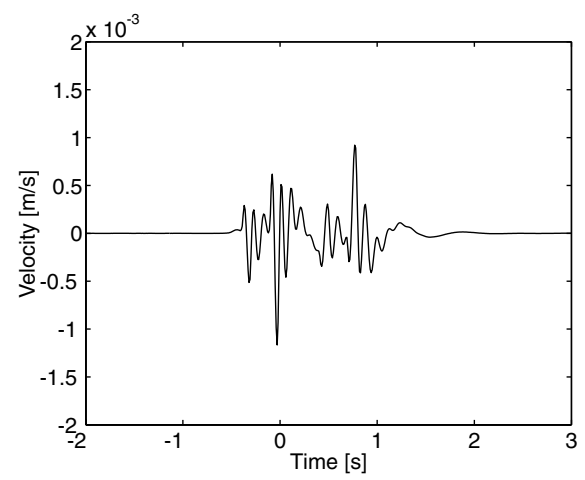

c. $v_{J}(t)$.

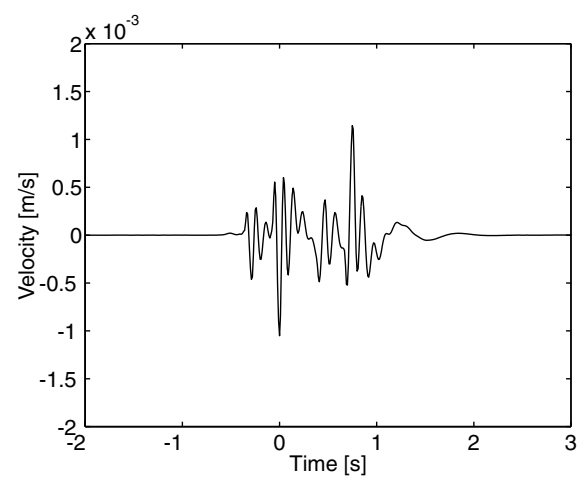

e. $v_{K}(t)$.

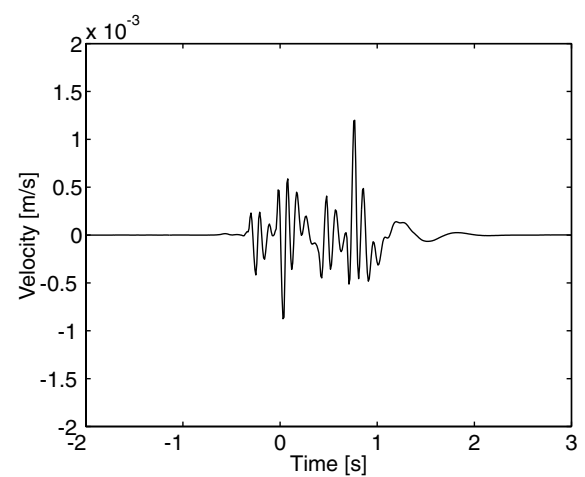

g. $v_{L}(t)$.

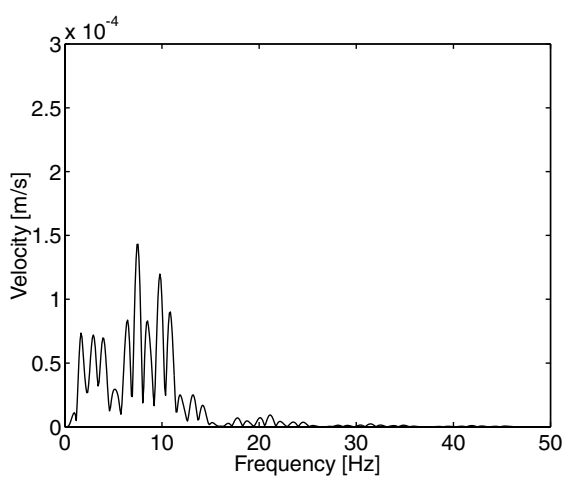

b. $\hat{v}_{I}(w)$.

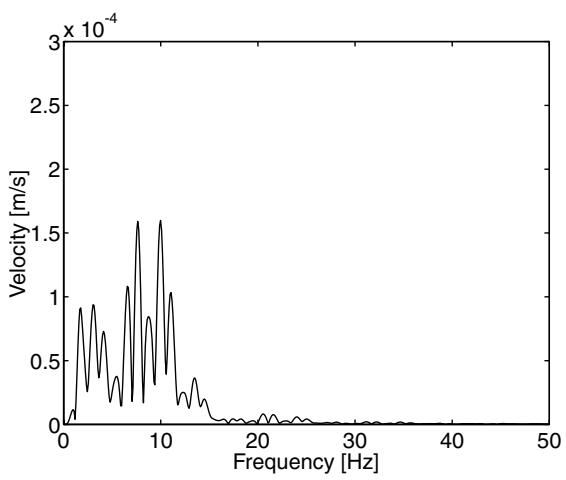

d. $\hat{v}_{J}(w)$.

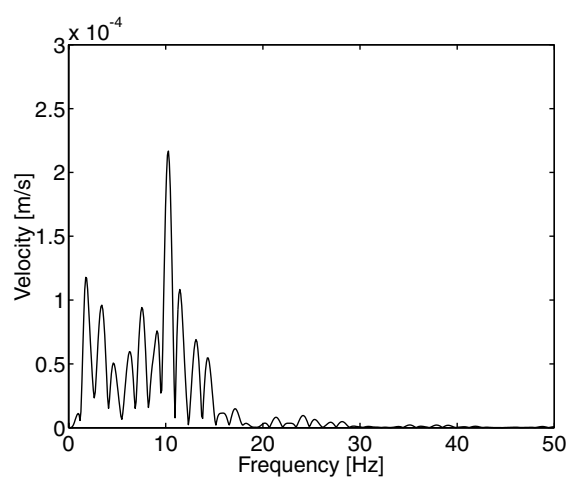

f. $\hat{v}_{K}(w)$.

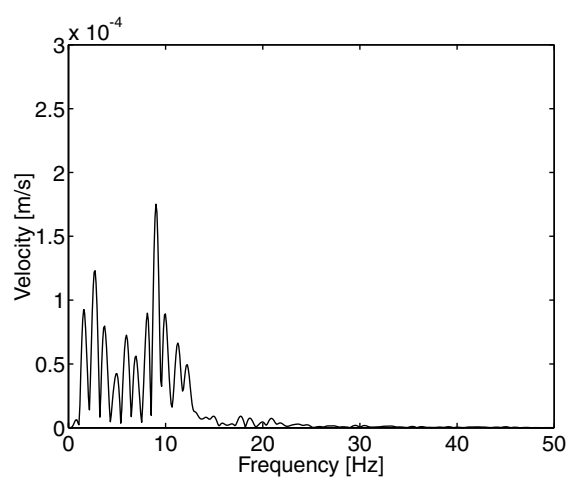

h. $\hat{v}_{L}(w)$.

Fig. 10. Time history (left) and frequency content (right) of the vertical velocity in the points $I, J, K$ and $L$ on a line parallel to the longitudinal axis of the road. 

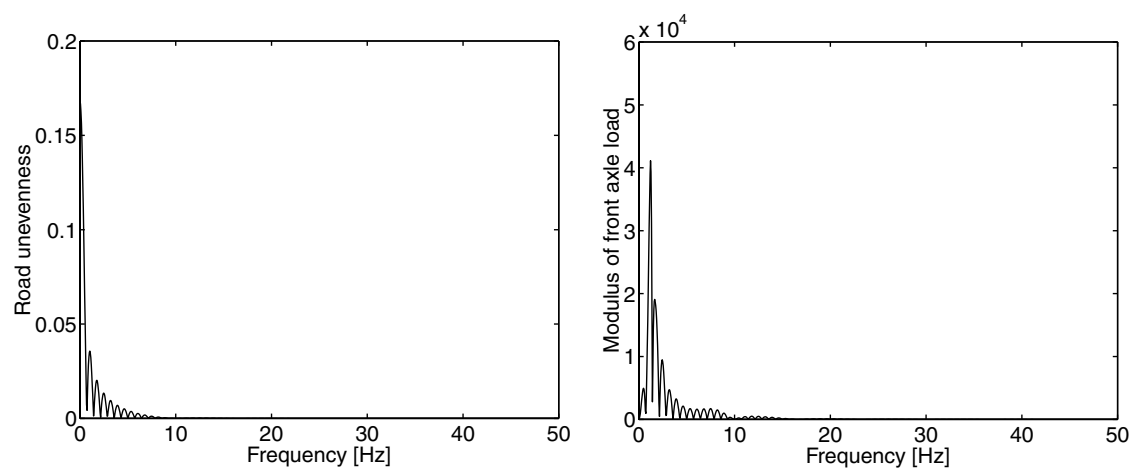

a. $v=8 \mathrm{~m} / \mathrm{s}$
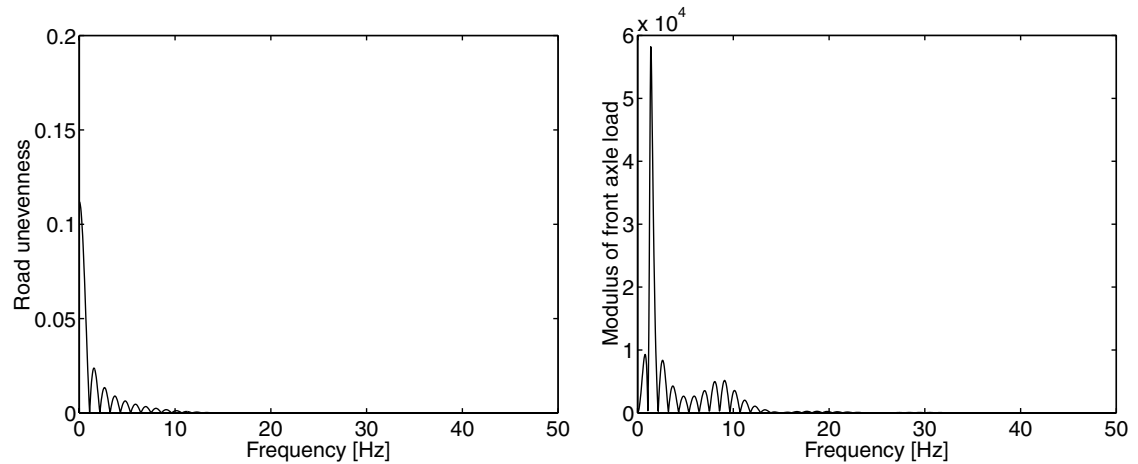

b. $v=12 \mathrm{~m} / \mathrm{s}$
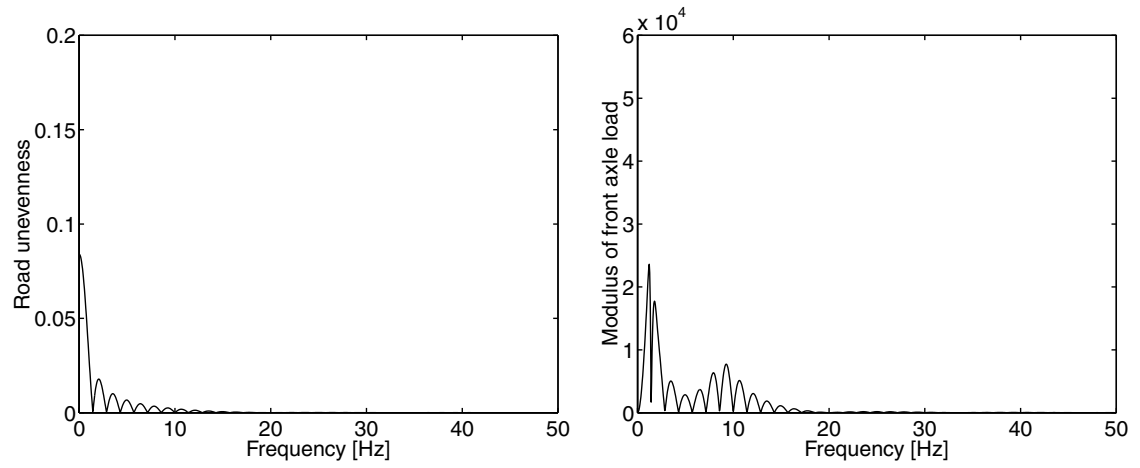

c. $v=16 \mathrm{~m} / \mathrm{s}$
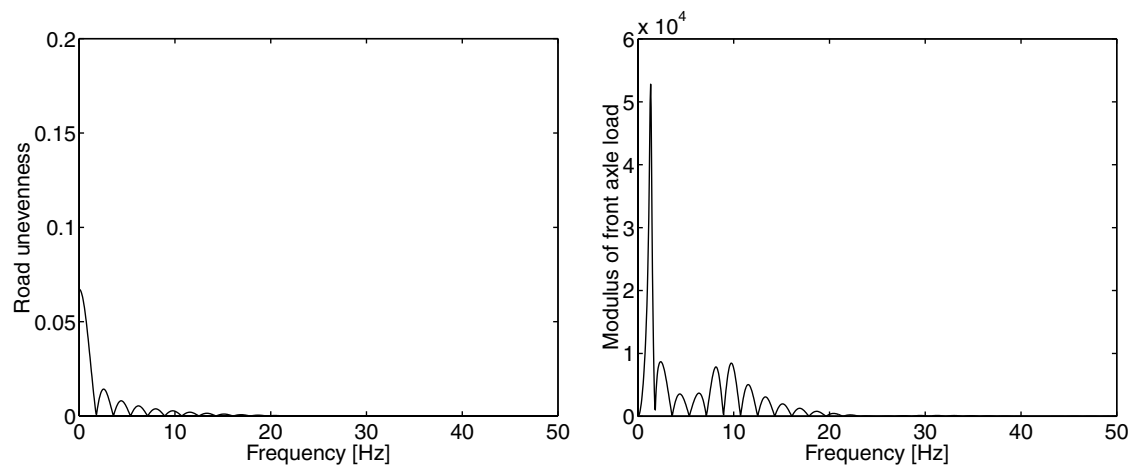

d. $v=20 \mathrm{~m} / \mathrm{s}$

Fig. 11. Frequency content of the road profile experienced by the vehicle axles (left) and frequency content of the front axle load (right) for a vehicle speed $v$ equal to $8,12,16$ and $20 \mathrm{~m} / \mathrm{s}$. 

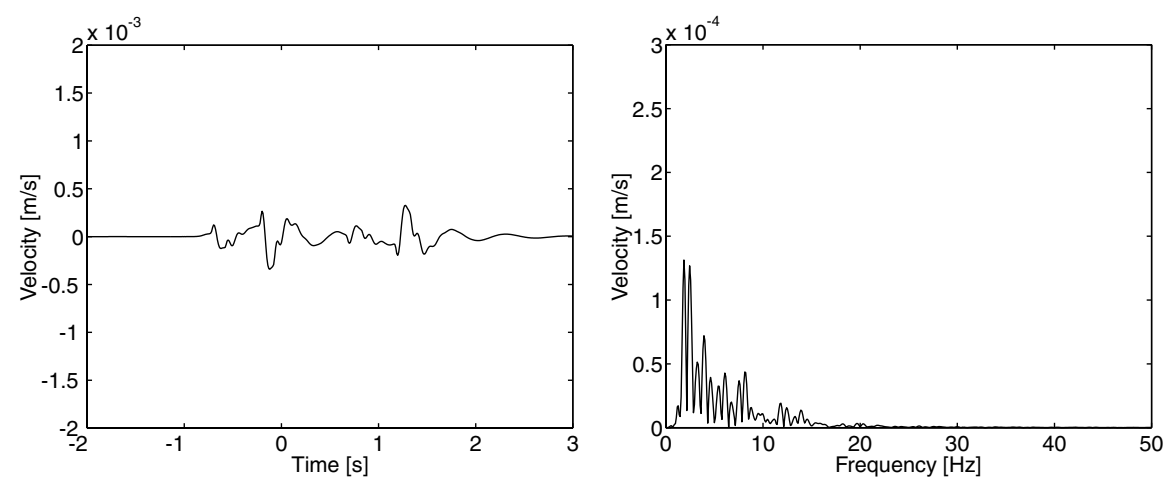

a. $v=8 \mathrm{~m} / \mathrm{s}$.
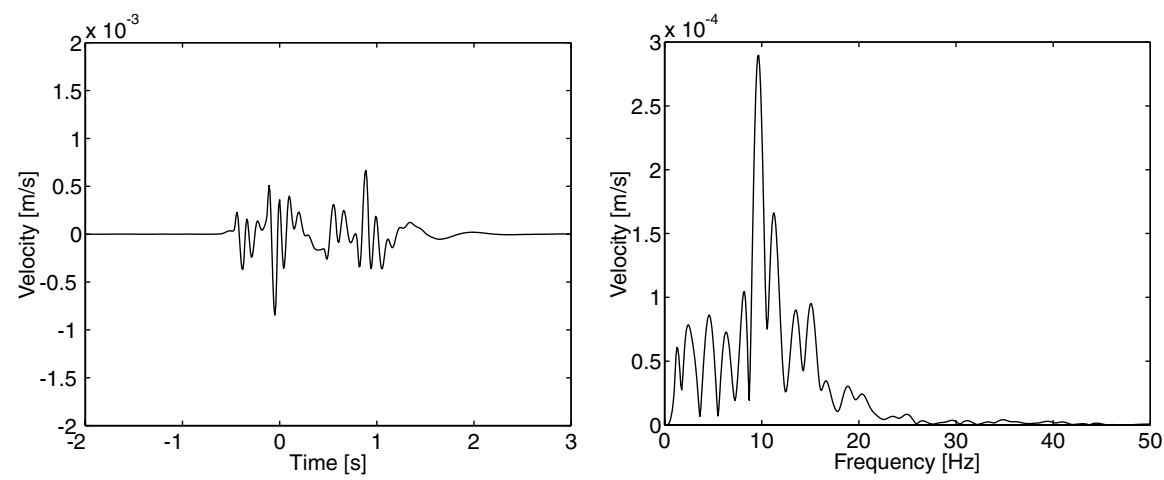

b. $v=12 \mathrm{~m} / \mathrm{s}$.
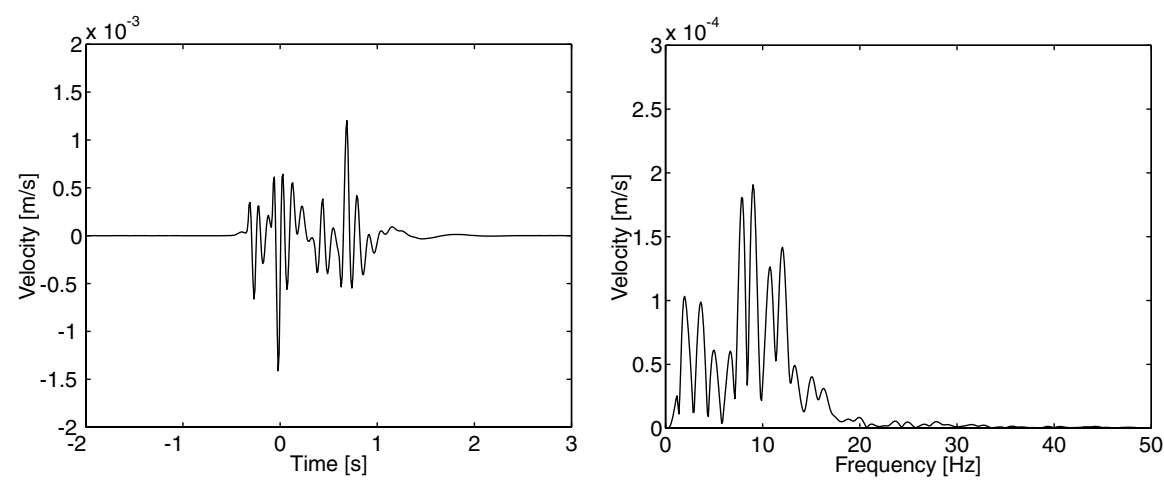

c. $v=16 \mathrm{~m} / \mathrm{s}$.
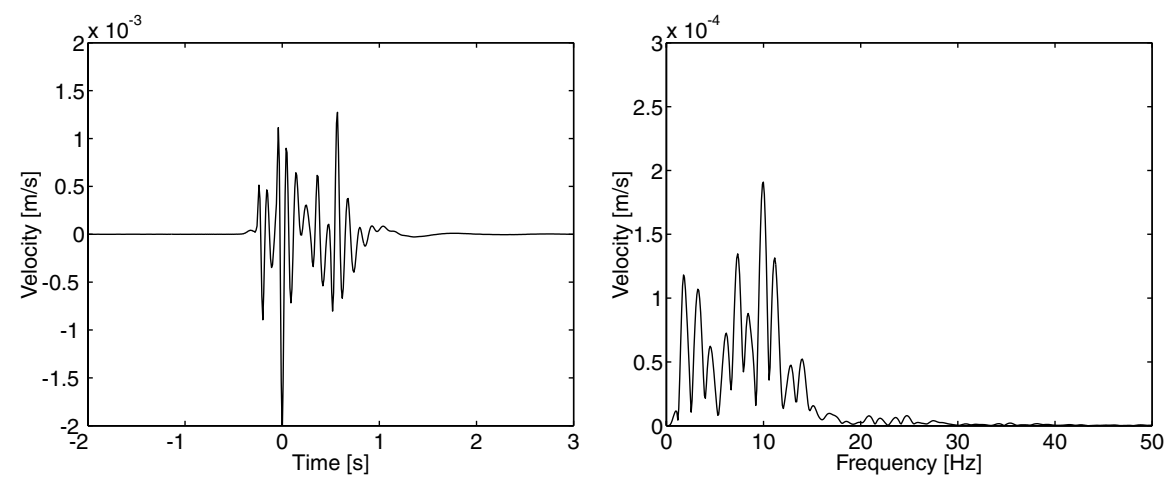

d. $v=20 \mathrm{~m} / \mathrm{s}$.

Fig. 12. Time history (left) and frequency content (right) of the vertical soil velocity in the point $B$ for a vehicle speed $v$ equal to $8,12,16$ and $20 \mathrm{~m} / \mathrm{s}$. 
propagation in the soil. As expected, larger vehicle speeds lead to increasing vibration levels.

\section{Acknowledgements}

The results presented in this paper have been obtained within the frame of the research project MD/01/040 "The study of determining factors for traffic induced vibrations in buildings". This research project is supported by the Prime Minister's Services of the Belgian Federal Office for Scientific, Technical and Cultural Affairs and is part of the Sustainable Mobility programme. This support is hereby gratefully acknowledged.

\section{References}

[1] Al-Hunaidi MO, Rainer JH. Control of traffic induced vibration in buildings using vehicle systems suspension. Soil Dynamics and Earthquake Engineering 1996;15:245-54.

[2] Aubry D, Clouteau D. A regularized boundary element method for stratified media. In: Cohen G, Halpern L, Joly P, editors. Mathematical and numerical aspects of wave propagation phenomena, Proc. 1st Int. Conf., Strasbourg, France, 23-26 April 1991, Philadelphia: SIAM, 1991. p. 660-8 (SIAM, INRIA).

[3] Aubry D, Clouteau D. A subdomain approach to dynamic soil-structure interaction. In: Davidovici V, Clough RW, editors. Recent advances in earthquake engineering and structural dynamics, Nantes: Ouest Editions/AFPS, 1992. p. 251-72.

[4] Koninklijk Besluit 9 oktober 1998. Koninklijk Besluit tot bepaling van de vereisten voor de aanleg van verhoogde inrichtingen op de openbare weg en van de technische voorschriften waaraan die moeten voldoen. Belgisch Staatsblad 28 oktober, 1998.

[5] Cebon D. Interaction between heavy vehicles and roads. Technical report. Cambridge University Engineering Department, 1993.

[6] Clauwaert C. Twee rekenmethoden voor een eenassig voertuig ter bepaling van de dynamische krachten op een wegprofiel en hun experimentele verificatie. Technical Report RV 24/84. Opzoekingscentrum voor de Wegenbouw, 1984.

[7] Clouteau D. MISS, Revision 2.1. Notice Utilisateur. Laboratoire de Mécanique des Sols, Structures et Matériaux, Ecole Centrale de Paris, 1993.

[8] Clouteau D, Aubry D, Bonnet G. Modeling of wave propagation due to fixed or mobile sources, wave propagation and reduction of vibrations. Bochum: Berg-verlag, 1994 (p. 109-21).

[9] Clouteau D, Aubry D, Elhabre ML, Savin E. Periodic and stochastic bem for large structures embedded in an elastic half-space, mathematical aspects of boundary element methods 1999 (p. 91-102).

[10] Courage WMG. Bronmodel wegverkeer. Technical report 93-CONR0056-04. Nederlandse Organisatie voor Toegepast Natuurwetenschappelijk Onderzoek, September 1993.

[11] de Barros FCP, Luco JE. Moving Green's functions for a layered viscoelastic halfspace. Technical report. Department of Applied Mechanics and Engineering Sciences, University of California, San Diego, La Jolla, CA, May 1992.

[12] Degrande G, Alerts W. Spectral version 7.01: a direct stiffness formulation for harmonic and transient wave propagation in layered dry, saturated and unsaturated poroelastic media. User's manual, Department of Civil Engineering, Katholieke Universiteit Leuven, 1999.

[13] Degrande G, De Roeck G, Van den Broeck P, Smeulders D. Wave propagation in layered dry, saturated and unsaturated poroelastic media. International Journal of Solids and Structures (Poroelasticity Maurice Biot Memorial Issue), A 1998;35(34-35):4753-78.

[14] Descornet G, Boulet M. Road surface design and tyre/road surface interactions. In Tyretech'95, Rapra Technology Ltd and European Rubber Journal, 1995.

[15] Dodds CJ, Robson JD. The description of road surface roughness. Journal of Sound and Vibration 1973;31(2):175-83.

[16] Frúba L. Vibration of solids and structures under moving loads. 3rd ed. London: Thomas Telford, 1999.

[17] Gillespie TD, Karamihas SM, Sayers MW, Nasim MA, Hansen W, Ehsan N, Cebon D. Effects of heavy-vehicle characteristics on pavement response and performance. Technical Report 353. NCHRP, Transportation Research Board, Washington DC, 1993.

[18] Grundmann H, Lieb M, Trommer E. The response of a layered halfspace to traffic loads moving along its surface. Archive of Applied Mechanics 1999;69:55-67.

[19] Hao H, Ang TC. Analytical modelling of traffic-induced ground vibrations. Journal of the Engineering Mechanics Division, Proceedings of the ASCE 1998;124(8):921-8.

[20] Hughes TJR. The finite element method: linear static and dynamic finite element analysis. Englewood Cliffs, NJ: Prentice-Hall, 1987.

[21] Hunt HEM. Modelling of road vehicles for calculation of traffic-induced ground vibrations. Journal of Sound and Vibration 1991;144(1):41-51.

[22] Hunt HEM. Stochastic modelling of traffic-induced ground vibration. Journal of Sound and Vibration 1991;144(1):53-70.

[23] ISO8608. Mechanical vibration, road surface profiles. Reporting of measured data, 1991.

[24] Kausel E, Roësset JM. Stiffness matrices for layered soils. Bulletin of the Seismological Society of America 1981;71(6):1743-61.

[25] Knothe K, Wu Y. Receptance behaviour of railway track and subgrade. Archive of Applied Mechanics 1998;68:457-70.

[26] Lombaert G, Degrande G. Study of determining factors for traffic induced vibrations in buildings. First biannual report BWM-199901. Department of Civil Engineering, Katholieke Universiteit Leuven, January 1999. DWTC Research Programme Sustainable Mobility. Research Project MD/01/040.

[27] Lombaert G, Degrande G. Study of determining factors for traffic induced vibrations in buildings. Second biannual report BWM1999-04. Department of Civil Engineering, Katholieke Universiteit Leuven, July 1999DWTC. Research Programme Sustainable Mobility, Research Project MD/01/040.

[28] Lombaert G, Degrande G, Clouteau D. Deterministic and stochastic modelling of free field traffic induced vibrations. In: Pereira $P$, Miranda V, editors. International Symposium on the Environmental Impact of Road Pavement Unevenness, Porto, Portugal, March, 1999. p. $163-76$.

[29] Luco JE, Apsel RJ. On the Green's functions for a layered half-space. Part I. Bulletin of the Seismological Society of America 1983;4:909-29.

[30] Mamlouk MS. General outlook of pavement and vehicle dynamics. Journal of Transportation Engineering, Proceedings of the ASCE 1997;123(6):515-7.

[31] Mandel J, Avramesco A. Déplacements produits par une charge mobile à la surface d'un semi-espace élastique. Comptes rendus hebdomadaires des séances de l'académie des sciences Paris. Serie D: Sciences Naturelles 1961;252:3730-2.

[32] Prognosemodel trillingshinder NN. Technical Report 95-2. Civieltechnisch Centrum Uitvoering Research en Regelgeving. February 1995.

[33] Payton RG. An application of the dynamic Betti-Rayleigh reciprocal theorem to moving point loads in elastic media. Quarterly of Applied Mathematics 1964;21(4):299-313.

[34] Svay J. Modélisation de la sismique de puits en puits-horizontal. $\mathrm{PhD}$ thesis, Ecole Centrale de Paris, 1995.

[35] Van den Broeck P, De Roeck G. The vertical receptance of track including soil-structure interaction. In: Frúba L, Náprstek J, editors. Proceedings of the 4th European Conference on Structural Dynamics: Eurodyn'99, Prague, Czech Republic, June 7-10 1999. Rotterdam: Balkema AA, 1999. p. 837-42.

[36] Wambold JC, Defrain LE, Hegmon RR, Macghee K, Reichert J, Spangler EB. State of the art of measurement and analysis of road roughness. Transportation Research Record 1981;836:21-9. 